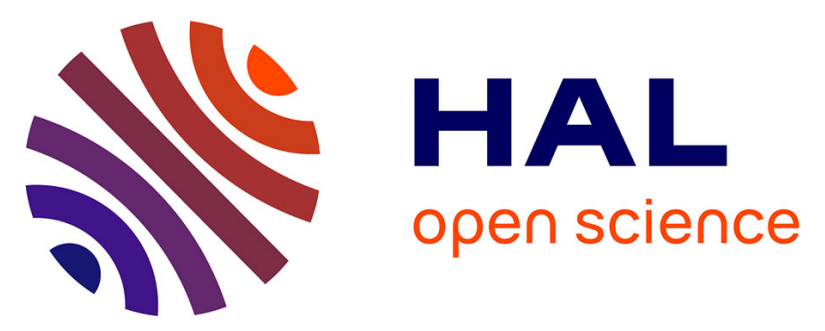

\title{
Response of intertidal benthic microalgal biofilms to a coupled light-temperature stress: evidence for latitudinal adaptation along the Atlantic coast of Southern Europe.
}

\author{
Martin Laviale, Alexandre Barnett, João Ezequiel, Bernard Lepetit, Silja \\ Frankenbach, Vona Méléder, João Serôdio, Johann Lavaud
}

\section{To cite this version:}

Martin Laviale, Alexandre Barnett, João Ezequiel, Bernard Lepetit, Silja Frankenbach, et al.. Response of intertidal benthic microalgal biofilms to a coupled light-temperature stress: evidence for latitudinal adaptation along the Atlantic coast of Southern Europe.. Environmental Microbiology, 2015, pp.3662-3677. 10.1111/1462-2920.12728 . hal-01097838

\section{HAL Id: hal-01097838 \\ https://hal.science/hal-01097838}

Submitted on 9 Jan 2015

HAL is a multi-disciplinary open access archive for the deposit and dissemination of scientific research documents, whether they are published or not. The documents may come from teaching and research institutions in France or abroad, or from public or private research centers.
L'archive ouverte pluridisciplinaire HAL, est destinée au dépôt et à la diffusion de documents scientifiques de niveau recherche, publiés ou non, émanant des établissements d'enseignement et de recherche français ou étrangers, des laboratoires publics ou privés. 
1 Response of intertidal benthic microalgal biofilms to a coupled light-temperature stress: evidence for latitudinal adaptation along the Atlantic coast of Southern Europe.

3

4 Martin Laviale, ${ }^{1 *}$ Alexandre Barnett, ${ }^{2}$ João Ezequiel, ${ }^{1}$ Bernard Lepetit, ${ }^{2 \#}$ Silja Frankenbach, ${ }^{1}$

5 Vona Méléder, ${ }^{2,3}$ João Serôdio ${ }^{1}$ and Johann Lavaud ${ }^{2}$

6

$7{ }^{1}$ Departamento de Biologia and CESAM - Centro de Estudos do Ambiente e do Mar, 8 Universidade de Aveiro, Campus de Santiago, 3810-193 Aveiro, Portugal

92 UMRi7266 LIENSs 'Littoral, Environnement et Sociétés', CNRS/Université de La

Rochelle, Institut du Littoral et de l'Environnement, 2 rue Olympe de Gouges, 17000 La

Rochelle, France.

${ }^{3}$ LUNAM Université, Université de Nantes, EA 2160 MMS 'Mer, Molécules, Santé', 2 rue de la Houssinière, BP 92 208, 44322, Nantes Cedex 3, France

\# Current address: Plant Ecophysiology, Department of Biology, University of Konstanz, Universitätsstraße 10, 78457 Konstanz, Germany

* Corresponding author:

Departamento de Biologia and CESAM - Centro de Estudos do Ambiente e do Mar, Universidade de Aveiro, Campus de Santiago, 3810-193 Aveiro, Portugal

Phone: +351 234370 968; Fax: +351 234372 587; E-mail: martin.laviale.bio@gmail.com

Running title: microphytobenthos response to light-temperature stress 


\section{Summary:}

Although estuarine microphytobenthos (MPB) is frequently exposed to excessive light and temperature conditions, little is known on their interactive effects on MPB primary productivity. Laboratory and in situ experiments were combined to investigate the short-term joint effects of high light (HL) and high temperature $\left(37^{\circ} \mathrm{C} v s .27^{\circ} \mathrm{C}\right)$ on the operating efficiency of photoprotective processes (vertical migration $v s$. non-photochemical quenching: NPQ) exhibited by natural benthic diatom communities from two intertidal flats in France (FR) and Portugal (PT). A clear latitudinal pattern was observed, with PT biofilms being more resistant to HL stress, regardless the effect of temperature, and displaying a lower relative contribution of vertical migration to photoprotection and a stronger NPQ in situ. However, higher temperature leads to comparable effects, with photoinhibition increasing to about 3times (i.e. from 3 to $10 \%$ and from 8 to $22 \%$ in PT and FR sites, respectively). By using a number of methodological novelties in MPB research (lipid peroxidation quantification, Lhcx proteins immunodetection), this study brings a physiological basis to the previously reported depression of MPB photosynthetic productivity in summer. They emphasize the joint role of temperature and light in limiting, at least transiently (i.e. during emersion), MPB photosynthetic activity in situ. 


\section{Introduction}

Estuarine tidal flats are one of the most productive ecosystems on Earth, largely owing to the photosynthetic productivity of benthic microalgae communities, or microphytobenthos (MPB) (Underwood and Kromkamp, 1999). MPB communities are often dominated by motile pennate diatoms (Haubois et al., 2005; Méléder et al., 2007; Ribeiro et al., 2013). In fine sediment habitats, they undergo rhythmic vertical migration patterns in the upper layers of the sediment following tidal/dial cycles (Saburova and Polikarpov, 2003; Consalvey et al., 2004; Coelho et al., 2011). During daylight emersion, the upward migration of cells results in the formation of transient photosynthetic biofilms which are thus periodically exposed to variable and extreme environmental conditions, due to the complex interplay of timing of tidal exposure and weather conditions (Admiraal 1984; Paterson and Hagerthey, 2001). Excessive light exposure generates intra-cellular oxidative stress (Roncarati et al., 2008; Waring et al., 2010) which can lower photosynthetic efficiency (i.e. photoinhibition; Wu et al., 2012; Cartaxana et al., 2013) and ultimately community-level primary productivity (Blanchard et al., 1996; Guarini et al., 2006). Furthermore, benthic diatom's photosynthesis often operates under the combined action of high light and other potentially stressful environmental factors such as extreme temperature (Blanchard et al., 1997; Serôdio and Catarino, 1999). Although photosynthesis is known to be highly sensitive to temperature (Mathur et al., 2014), effects of high temperature on MPB productivity, either alone or in combination with excess light have received little attention (Grant, 1986; Vieira et al., 2013 and references therein). However, recent results showed implications on both dial and seasonal scales (Hancke et al., 2014). On a longer term perspective, the cumulative effects of light and temperature could be relevant as well, as climate change is expected to influence not only average values but also the frequency and the intensity of extreme events such as heat waves (Schär et al., 2004; Stott et al., 2004; Solomon et al., 2007). 
The actual photoinhibitory effects depend on the photoadaptive strategy of the diatoms of MPB, i.e. the operating efficiency of a range of mechanisms which include 'behavioural' and 'physiological' photoprotective processes (Barnett et al., 2014). The 'behavioural photoprotection' consists of a strong negative phototaxis resulting in downward migration under supersaturating light intensities (Kromkamp et al., 1998; Perkins et al., 2010; Cartaxana et al., 2011; Serôdio et al., 2012). The vertical migration of cells within the steep light gradient of the sediment photic zone (Paterson and Hagerthey, 2001; Cartaxana et al., 2011) has been hypothesized to allow for the optimization of light harvesting and the avoidance of excess light (Admiraal, 1984). Strong evidence for a photoprotective role of vertical migration was provided by the use of the diatom motility inhibitor Latrunculin A (Lat A) on undisturbed biofilms (Perkins et al., 2010; Cartaxana et al., 2011; Serôdio et al., 2012). 'Physiological photoprotection' mainly includes the excess energy-dissipative non-photochemical quenching of chlorophyll (Chl) $a$ fluorescence (NPQ). NPQ is mainly controlled by the presence of the xanthophyll pigment diatoxanthin (DT) and of Lhcx proteins in the light-harvesting complexes of photosystem II (PSII) (Depauw et al., 2012; Lepetit et al., 2012, 2013; Lavaud and Goss, 2014). In diatoms, DT is produced by the (dark/low light) reversible lightdependent conversion of the xanthophyll diadinoxanthin (DD) in the so called xanthophyll cycle (XC) (Goss and Jakob, 2010). Besides its involvement in NPQ, it seems to have another function as antioxidant (Lepetit et al., 2010).

Despite the crucial role of NPQ and XC in the photoprotective response of diatoms to excessive fluctuating light regimes, especially in field situations (Brunet et al., 2010; Lavaud and Lepetit, 2013; Lavaud and Goss, 2014), they have only scarcely been studied in MPB. They show a relation to diurnal and tidal cycles, season, latitude (Serôdio et al., 2005; van Leeuwe et al., 2008; Chevalier et al., 2010), to vertical position of diatoms within the sediment (Jesus et al., 2009; Cartaxana et al., 2011) or along the intertidal elevation gradient 
(Jesus et al., 2009), with significant differences between the main growth forms (i.e. epipelic and epipsammic: Cartaxana et al., 2011; Barnett et al., 2014). As for the implication of Lhcx proteins in diatom NPQ, its characterization has been limited to few model species (Bailleul et al. 2010; Zhu et al., 2010). Lhcx1 is involved probably at least by binding DT (Bailleul et al., 2010; Büchel, 2014). It is present at low light and its transcript level/synthesis is slightly enhanced under high light (HL) (Bailleul et al., 2010; Wu et al., 2012; Lepetit et al., 2013). While the transcript levels/synthesis of other examined isoforms (i.e. Lhcx2, Lhcx3, Lhcx6) strongly increase during HL (Zhu et al., 2010; Lepetit et al., 2013) and temperature stress (for Lhcx6; Wu et al., 2012), their exact physiological role remains unknown, although Lhcx3 and Lhcx6 are suspected to be involved in the binding of de novo synthesized DT and/or the sustain part of NPQ (i.e. qI) during a prolonged HL stress (Zhu et al., 2010; Lepetit et al., 2013).

This work intended to study the combined effects of high light (HL) and high temperature on the photophysiology of intertidal diatom-dominated MPB communities. Light stress-recovery experiments (LSRE) were performed to distinguish physiological photoprotection efficiency from photoinhibitory effects, and to quantify behavioural photoprotection (Serôdio et al., 2012). Until now, these processes have been characterized only to the extent of chlorophyll fluorescence measurements and XC pigments analysis. The present study combines chlorophyll fluorescence imaging, pigment analysis and for the first time on intact biofilms, lipid peroxidation quantification and immunodetection of Lhcx proteins. LSRE were performed on MPB from two locations in France and Portugal with different solar exposure and temperature regimes, likely to support the establishment of diatom communities with contrasting photo- and thermo-adaptive strategies. Moreover, the potential role of temperature in modulating the HL-induced stress was investigated by carrying out LSRE at two experimental temperature conditions ('optimal' $v s$. high temperature). In parallel, the 
117 estimated photosynthetic and protective indices were further compared with field situation at 118 the two sites during a typical summer diurnal emersion. 


\section{Results}

Environmental conditions, in situ photosynthetic activity and taxonomic composition of microphytobenthos in PT and FR sites

Environmental conditions and MPB photosynthetic activity were assessed during typical summer diurnal emersion at both Portuguese (PT) and French (FR) intertidal flats. The Photosynthetic Active Radiation (PAR) reached its daily maximum $\left(2000 \mu \mathrm{mol}\right.$ photons $\mathrm{m}^{-2} \mathrm{~s}^{-}$ ${ }^{1}$ ) at both sites (Fig. 1A-B) with a comparable light dose over the emersion ( 19 to $23 \mathrm{~mol}$ photons $\mathrm{m}^{-2}$, Table S1). Temperature was higher at PT site (Fig. 1A-B). Average temperatures at the sediment surface were $37.5^{\circ} \mathrm{C}$ and $28.8^{\circ} \mathrm{C}$ for PT and $\mathrm{FR}$ sites, respectively. Temperature decreased with sediment depth with a stronger effect in PT site $\left(-7^{\circ} \mathrm{C}\right.$ and $-6^{\circ} \mathrm{C}$ in the first $0.5 \mathrm{~cm}$ for PT and FR sites, respectively: Table S1, Fig. 1A-B).

At the beginning of emersion, the effective PSII quantum yield (ФPSII) was close to its optimum at both sites ( 0.70: Fig. 1C-D, open squares). It decreased/increased opposite to the PAR evolution over the emersion period, reaching values as low as $\sim 0.40$. The maximal non-photochemical quenching of Chl $a$ fluorescence (NPQ $\mathrm{Nax}_{\text {ax }}$ ) was about 4-5 at PT site and lower than 1 at FR site at the beginning of emersion (Fig. 1C-D, closed circles). It decreased continuously at PT site to reach values around 3 at the end of the emersion, while it covaried with PAR at FR site, reaching a maximum value of about 6 (matching the sudden increase in PAR level) and values of 3-4 at the end of the emersion.

At both sites, MBP communities were dominated by epipelic (i.e. motile) benthic diatoms of the genus Navicula (Table S2). Navicula phyllepta sensu lato (Vanelslander et al., 2009) was the dominant species at PT site (relative abundance: $44 \%$ ) while FR site was co-dominated by N. spartinetensis (33\%) and N. phyllepta s.1. (28\%).

\section{Comparison between in situ and experimental conditions}


The two temperature treatments used for the laboratory experiments during the LSREs were $27.4 \pm 1.2^{\circ} \mathrm{C}$ and $37.3 \pm 0.7^{\circ} \mathrm{C}$ (thereafter named $27^{\circ} \mathrm{C}$ and $37^{\circ} \mathrm{C}$ temperature treatments, respectively), which was close to the average temperatures monitored at the sediment surface for both sites (see above and Table S1). The light exposure of $3 \mathrm{~h}$ of $1200 \mu \mathrm{mol}$ photons $\mathrm{m}^{-2} \mathrm{~s}^{-}$ ${ }^{1}$ represented a light dose of 12.96 mol photons $\mathrm{m}^{-2}$ (Serôdio et al., 2012). This light dose was reached after 2 h 53 min and 3 h 34 min in PT and FR sites, respectively (Table S1).

\section{LSRE-induced photoinhibition and NPQ in sediment from FR site}

ФPSII remained constant in samples maintained under LL throughout the experiment $(0.66 \pm$ 0.02, Fig. 2). In comparison, samples exposed to HL exhibited dramatic changes over time (time: P $<0.001$, see Table S3a for detailed statistical outputs). After 3h HL, ФPSII decreased down to values between $0.13 \pm 0.03\left(37^{\circ} \mathrm{C}+\right.$ Lat $\left.\mathrm{A}\right)$ and $0.34 \pm 0.02\left(27^{\circ} \mathrm{C} \mathrm{Ctrl}\right)$. It increased during LL recovery but did not reach back its initial level $\left(0.46 \pm 0.05\left(37^{\circ} \mathrm{C}+\mathrm{Lat} \mathrm{A}\right)\right.$ and $0.61 \pm 0.01\left(27^{\circ} \mathrm{C} \mathrm{Ctrl}\right)$. The differences observed between temperature and chemical treatments were significant (temperature: $\mathrm{P}<0.001$; chemical: $\mathrm{P}<0.01$; Table S3a), and they both increased with time (time $\times$ temperature: $\mathrm{P}<0.001$; time $\times$ chemical: $\mathrm{P}<0.05$; Table S3a). Similarly, NPQ of samples maintained under LL remained constant $(0.38 \pm 0.04$, Fig. 3$)$ and changed over time according to light (time: $\mathrm{P}<0.001$, Table S3b): it increased under HL (between $4.4 \pm 0.5$ and $3.4 \pm 0.4$ from $37^{\circ} \mathrm{C}+$ Lat $\mathrm{A}$ and $27^{\circ} \mathrm{C} \mathrm{Ctrl}$ treatments, respectively) but only partially relaxed during the subsequent 15 min LL incubation (between $1.9 \pm 0.1$ and $1.1 \pm 0.1$; Fig. 3). The effect of temperature was highly significant (temperature: $\mathrm{P}<0.001$, Table S3b) and the observed differences increased with time (time $\times$ temperature: $\mathrm{P}<0.001$; Table S3b). In comparison, the effect of lat A was less significant (chemical: $\mathrm{P}<0.05$ and time $\times$ temperature: $\mathrm{P}=0.11$; Table $\mathrm{S} 3 \mathrm{~b}$ ) . 
LSRE-induced allomerization of Chl a and xanthophyll cycle in sediment from FR site

All samples exhibited typical diatom pigment signatures, including Chl $a$, Chls $c$, fucoxanthin, the carotenoid $\beta, \beta$ carotene (data not shown) and the xanthophyll cycle pigments DD and DT. The allomer form of Chl $a$ (Chl $a$-allo) accumulated during the LSRE as illustrated by the Chl $a$ allomerization molar ratio (AR= Chl $a$-allo / total Chl $a \times 100$, Fig. 4A). AR increased 2-fold under HL and remained stable thereafter (time: $\mathrm{P}<0.001$; Table S3c). No significant changes were observed with temperature (temperature: $\mathrm{P}=0.48$; Table S3c), whereas AR was significantly higher in +Lat A samples than in Ctrl (chemical: P < 0.01 ; Table S3c), with mean maximum values of $11.9 \pm 5.0 \%$ and $8.4 \pm 2.1 \%$, respectively (Fig. S1). AR did not significantly change in samples maintained in LL during $3 \mathrm{~h}(5.9 \pm$ $2.7 \%$ on average).

The pool of DD+DT (in mol. $100 \mathrm{~mol} \mathrm{Chl} a^{-1}$ ) increased $~ 3$-fold under HL and remained stable during the LL recovery (Fig. $4 \mathrm{~B}$, time: $\mathrm{P}<0.001$; Table $\mathrm{S} 3 \mathrm{~d}$ ). Overall, it reached higher values at $37^{\circ} \mathrm{C}$ than at $27^{\circ} \mathrm{C}$ (temperature: $\mathrm{P}<0.01$; Table S3d) but it was comparable in $\mathrm{Ctrl}$ and + Lat $\mathrm{A}$ samples $(\mathrm{P}=0.58$; Table $\mathrm{S} 3 \mathrm{~d})$. At $37^{\circ} \mathrm{C}, \mathrm{DD}+\mathrm{DT}$ increased even in the samples maintained under LL for $3 \mathrm{~h}$ (from $15.0 \pm 4.0$ to $23.8 \pm 6.6 \mathrm{~mol} .100 \mathrm{~mol} \mathrm{Chl} a^{-1}$, Tukey HSD: $\mathrm{P}<0.05$, Fig. S2). DD de-epoxidation $(\mathrm{DES}=\mathrm{DT} / \mathrm{DD}+\mathrm{DT} \times 100)$ correlated well with light whatever the temperature in both $\mathrm{Ctrl}$ and Lat A-treated samples $(\mathrm{P}<0.001)$ (Fig. 4C-D). DES increased under HL and decreased during LL recovery while it remained stable in samples maintained in LL for $3 \mathrm{~h}(14.0 \pm 3.2 \%$ on average) (Fig. S3). DES was significantly higher in +Lat A samples than in Ctrl ones (chemical: $\mathrm{P}<0.001$; Table S3d), and at $37^{\circ} \mathrm{C}$ than at $27^{\circ} \mathrm{C}$ (temperature: $\mathrm{P}<0.001$; Table S3d) with maxima of $67.2 \pm 7.5 \%$ and $33.8 \pm 7.5 \%$ at $37{ }^{\circ} \mathrm{C}$ and $27{ }^{\circ} \mathrm{C}$, respectively, in +Lat A samples (Fig. S3). DES recovered much faster at $27^{\circ} \mathrm{C}$ than at $37^{\circ} \mathrm{C}$, especially for $\mathrm{Ctrl}$ samples. In contrast to $\mathrm{AR}$ and the DD+DT pool, interaction between time and temperature was significant for DES (time $\times$ 
temperature: $\mathrm{P}<0.001$; Table S3d). Moreover, NPQ and DES were significantly positively correlated according to the chemical treatment (Ctrl/+Lat A), i.e. the slope of the NPQ vs. DES linear regression was 2.5 lower in +Lat A samples (Fig. S4) while for both treatments the origin of the regression was similar and non-nul (Ctrl: $17.6 \pm 0.4$; +Lat A: $16.4 \pm 0.4)$, i.e. some DT was synthesized without NPQ development.

\section{LSRE-induced Lhcx synthesis in sediment from FR site}

The anti-FCP6 (i.e. Lhcx1) revealed a clear Lhcx isoform in FR samples (Fig. 5A). Its size of about $24 \mathrm{kDa}$ was slightly higher than the one of Lhcx 3 in Phaeodactylum tricornutum and its amount increased after $3 \mathrm{~h} \mathrm{HL}$ exposure especially in +Lat A samples. Interestingly, $N$. phyllepta s.l., the dominant species of the MPB assemblage, showed an Lhcx pattern similar to P. tricornutum so that three isoforms (Lhcx1, Lhcx2 and Lhcx3) could be identified. The anti-Lhcx6 from Thalassiosira pseudonana revealed two Lhcx isoforms in FR samples, the size of which was different from Lhcx6 and was neither present in HL exposed P. tricornutum cells (Fig. 5B). N. phyllepta showed two isoforms, one which size was slightly higher than Lhcx6 and the other one with a similar size to the 33-50 kDa isoform from FR samples. With such size, this isoform could be a hypothetic Lhcx dimer (given that the available sizes of Lhcx monomers deduced from the genomes of $P$. tricornutum, $T$. pseudonana and Fragilariopsis cylindrus range between 21 and $29 \mathrm{kDa}$ ) but different than in $P$. tricornutum. The 17-23 kDa isoform showed a size similar to Lhcx 1 in P. tricornutum and N. phyllepta (see Fig. 5A). Interestingly, the two isoforms reacted to light, temperature and Lat $\mathrm{A}$ in different ways: while the $17-23 \mathrm{kDa}$ isoform appeared not to react to any of the treatments, the $33-50 \mathrm{kDa}$ isoform positively reacted to $\mathrm{HL}$ and $37^{\circ} \mathrm{C}$ with an effect enhanced by Lat $\mathrm{A}$ at $37^{\circ} \mathrm{C}$ (Fig. 5C). 
LSRE-induced lipid peroxidation in sediment from FR site

Common markers of membrane lipid peroxidation (TBARS-thiobarbituric acide reactive substances) were quantified. In Lat A treated samples, TBARS content normalized to the surface microphytobenthos biomass ( $\mathrm{I}_{\text {diat }}$ biomass index) did not change significantly over time and was not significantly affected by chemical or temperature treatments $(\mathrm{P}=0.71$, 0.99 and 0.19 , respectively; Table S3f), exhibiting a mean value of $1.19 \pm 0.2910^{-6} \mathrm{nmol}$ eq MDA mL $L^{-1}$ (Fig. 6).

\section{Comparison between FR and PT sites: NPQ, photoinhibition, lipid peroxidation and Lhcx.} ФPSII and NPQ measured on PT samples at T0 $(0.67 \pm 0.02$ and $0.40 \pm 0.05$, respectively) were comparable to the one measured on FR ones (Fig.2 and 3: $0.66 \pm 0.01$ and $0.39 \pm 0.01$, respectively), and they exhibited the same general trend under HL stress. However, PT samples were less affected by the HL treatment, as ФPSII recovered faster under LL (site: P < 0.001, Table S4a), regardless of temperature or Lat A application (Fig. 7A). Moreover, NPQ did not relax entirely, but the level of this sustained NPQ was lower than in FR samples (site: $\mathrm{P}<0.01$, Table S4b), although post-hoc multiple comparison tests did not show any statistical differences between sites (Tukey HSD: P > 0.05; Fig. 7B).

For each site and temperature, the extent of photoinhibition and the contribution of vertical migration to the overall photoprotection capacity of MPB were estimated as in Serôdio et al. (2012) (Table 1). Photoinhibition was higher in FR than PT site but it increased similarly ( 3 fold) with temperature. The contribution of vertical migration to photoprotection remained below $15 \%$ but was always lower in PT biofilms $(<5 \%)$.

In Lat A treated samples, TBARS content normalized to surface biomass did not change significantly at PT site whatever the temperature (Fig. S5). Mean value was $3.26 \pm 0.6610^{-6}$ nmol eq MDA $\mathrm{mL}^{-1}$, which was significantly higher than for FR samples (t-test: $\left.\mathrm{P}<0.001\right)$. 
245 While the anti-FCP6 (i.e. Lhcx1) revealed two clear Lhcx isoforms in PT samples (Fig. 8), the 246 anti-Lhcx6 did not bring any signal probably due to its unspecificity as regards to the species 247 composing the microphytobenthic community of PT site. Their respective size were close 248 with one at about $23 \mathrm{kDa}$, the size of Lhcx 3 in P. tricornutum and N. phyllepta, and the other 249 one slightly higher (about $24 \mathrm{kDa}$ ) which was also present in FR samples (Fig. 5A). Both 250 isoforms (although the $24 \mathrm{kDa}$ reacted in a stronger way) were enhanced after $3 \mathrm{~h}$ of $\mathrm{HL}$ exposure as well as by the higher temperature; this effect was increased by the addition of Lat A. Interestingly, at $27^{\circ} \mathrm{C}$, the $24 \mathrm{kDa}$ isoform was not present under LL and $\mathrm{HL}$ exposure, it appeared with the addition of Lat A solely $\left(\mathrm{LL} 27^{\circ} \mathrm{C}+\right)$ and its content was increased by HL exposure $\left(\mathrm{HL} 27^{\circ} \mathrm{C}+\right.$ ). Similarly, the $23 \mathrm{kDa}$ isoform positively reacted to Lat A to a level even similar to $\mathrm{HL}$ exposure without Lat A (compare $27^{\circ} \mathrm{C} \mathrm{LL}+$ and $27^{\circ} \mathrm{C} \mathrm{HL}-$ ). 
258 In this study, higher temperature significantly increased photoinhibition susceptibility of epipelic MPB biofilm. Communities from the Portuguese (PT) site were clearly more resistant to a coupled high light-temperature stress, in comparison to biofilms from the French (FR) site. At both site, photoprotection was based on the interplay between physiological (NPQ, DT and Lhcx proteins) and behavioural (vertical motility) response, nevertheless PT biofilms displayed a lower relative contribution of vertical migration and a stronger NPQ. The apparent latitudinal pattern observed at the community level ('MPB biofilm') might be driven by the individual response of the respective dominant diatom species/ecotypes in each site. These different aspects are discussed below.

Evidence for a latitudinal adaptation in the response of epipelic MPB to a coupled lighttemperature stress

Our results suggest that PT MPB communities were adapted to a higher light and/or temperature environment than FR ones. Overall, PT samples were more resistant than FR ones to $\mathrm{HL}$ stress, regardless the effect of temperature. At $27^{\circ} \mathrm{C}$, PT control samples recovered almost entirely from HL exposure (97\%), and photoinhibition increased only from 3 to $10 \%$ at $37^{\circ} \mathrm{C}$. This trend was also obvious in situ: the time course and level of $\Phi$ PSII were comparable between sites despite the potentially more stressful conditions at PT site (similar light conditions but $8-9^{\circ} \mathrm{C}$ higher average surface temperature). One of the reasons 277 for this differential latitudinal adaptation might lie in the photoprotective strategies the two 278 MPB communities exhibited. PT MPB communities showed higher $\mathrm{NPQ}_{\max }$ average values, an indication of a strong(er) physiological photoprotective response (Serôdio et al., 2005). PT $\mathrm{NPQ}_{\max }$ was already high right from the beginning of the emersion although light intensity 
migration contributed less to the overall photoprotection capacity $(<5 \%)$ in comparison to FR biofilms. FR NPQ $\max$ tended to follow the fluctuations of light intensity along the emersion which would be in agreement with a more dynamics MPB response, regarding both motility and physiology. Only few studies have examined the link between seasonal and/or latitudinal photoacclimation and the coupling between behavioural and physiological photoprotection in MPB communities. A similar increase of migration contribution was reported for communities acclimated to lower irradiances (i.e. seasonal acclimation: Serôdio et al., 2012). Another study provided evidence for the differential role of migration $v s$. XC along a latitudinal gradient (Ireland, UK and Portugal), although the role of sediment type (i.e. mud vs. sand) could not be ruled out (van Leeuwe et al., 2008).

In contrast, the contribution of thermal adaptation is difficult to ascertain. Although PT samples were more resistant and resilient, higher temperature leads to comparable effects: photoinhibition increased to about 3-times (i.e. from 3 to $10 \%$ and from 8 to $22 \%$, in PT and FR sites, respectively) and lipid peroxidation was comparable. The pattern of the detected Lhcx isoforms was also similar, although no quantification was possible. Average surface and $-0.5 \mathrm{~cm}$ temperature conditions experienced by the FR and PT communities were clearly different. The fact that this difference was lower than the observed amplitude over an emersion could explain the apparent lack of temperature latitudinal pattern. This is in agreement with other comparative studies on short-term (i.e. over few hours) temperature effects on MPB photosynthesis (Grant, 1986; Blanchard et al., 1997; Hancke and Glud, 2004). Instead, the different average temperature conditions at PT and FR sites recorded in this study, which are representative of typical summer conditions in these areas (Guarini et al., 1997; Lillebo et al., 2010), might have played a role on a longer time scale. As temperature and light adaptations rely on similar strategies (Davison, 1991; this study, see below), it is likely that the difference in average temperatures influenced the susceptibility of 
MPB to photoinhibition, directly and/or via its photoacclimation status, together with e.g. daily light dose, day length and/or UV exposure.

The latitudinal pattern in ecophysiological characteristics observed at the community level coincided with a shift in the diatom species composition. Although it is difficult to separate 'community' response from 'individual species' response within the biofilm, it is possible that the observed responses at each site were driven by the few dominant species (representing c.a. $50 \%$ of the total abundance). The two dominant species, $N$. phyllepta s.l. and $\mathrm{N}$. spartinetensis, are known to be widespread along the European Atlantic and Northwestern coasts (Vanelslander et al., 2009; Witkowski et al., 2012). Epipelic diatoms generally exhibit a low NPQ, in comparison to non-motile ones (Barnett et al., 2014). This does not preclude the existence of interspecific variability between organisms sharing the same life style, considering both behavioural (Underwood et al., 2005; Du et al., 2010, 2012) and physiological photoprotective mechanisms (Barnett et al., 2014). Furthermore, the occurrence of $N$. phyllepta s.l. at both sites can be explained by the pseudocryptic feature of this taxonomic group. It comprises different closely related species morphologically indistinguishable but exhibiting important ecophysiological differences and environmental preferences (Vanelslander et al., 2009). To which extent the differences observed between PT and FR sites (i.e. stronger $\mathrm{NPQ}_{\max }$ in $\mathrm{PT}$ assemblage regardless of the stress treatment; different Lhcx patterns) can be explained by the differential relative abundances of $N$. phyllepta s.1. vs. N. spartinetensis and/or pseudopcryptic species or ecotypes of $N$. phyllepta

327 s.l is a question that remains to be answered.

\section{Higher temperature increases photoinhibition susceptibility in epipelic MPB}

330 To our knowledge, this is the first study which shows that on intact migratory MPB biofilms high temperature and HL acts synergistically in decreasing photosynthesis, a feature so far 
reported only for individual species (Salleh and McMinn, 2011). Other works have shown that temperature alone impacts photosynthesis in benthic diatoms, in monospecific cultures (Morris and Kromkamp, 2003; Yun et al., 2010), MPB suspensions (Blanchard et al., 1997), and intact MPB biofilms (Vieira et al., 2013). In conditions where photosynthesis is lightsaturated, benthic diatom photosynthesis can respond to a transient temperature increase if it remains within a $25-35^{\circ} \mathrm{C}$ range. The high temperature used here $\left(37.3 \pm 0.7^{\circ} \mathrm{C}\right)$ falls slightly outside this range, a situation likely to occur regularly in situ in summer, as confirmed by our field data.

In situ measurements showed that ФPSII correlated well with irradiance during the emersion period. During LSRE, a strong decrease was also observed after $3 \mathrm{~h}$ of HL exposure. Although the applied light dose was lower than in situ, our results show that it was strong enough to induce photoinhibition at the community level. The incomplete recovery of $\Phi$ PSII after 15 min LL coincided with a sustained phase of NPQ which was induced during the prolonged HL exposure. This can be partly attributed to photoinhibition and illustrates the physiological response to harsh stress (Zhu et al., 2010; Wu et al., 2012; Lavaud and Lepetit, 2013). At optimal temperature $\left(27^{\circ} \mathrm{C}\right.$; see Blanchard et al., 1997 and Experimental procedures section), photoinhibition remained below $20 \%$, which is consistent with a previous study using a similar experimental approach (Serôdio et al., 2012). Photoinhibitory effects may be attributed to the progressive accumulation of reactive oxygen species (ROS, Roncarati et al., 2008; Waring et al., 2010), as evidenced by the increase of AR at the end of LSRE. Indeed, ROS have been shown to be directly involved in Chl $a$ allomerization (Hynninen et al., 2010 and references therein). This is also consistent with the accumulation of Chl $a$ allomers in response to oxidative stress in the diatom $P$. tricornutum (Cid et al., 1995). When superimposed to HL stress, significantly increased photoinhibition (c.a. 3-times increase in the controls from 27 to $37^{\circ} \mathrm{C}$ ) which is not surprising as PSII is the most thermosensitive 
component of the photosynthetic apparatus (Mathur et al., 2014). Nevertheless, the amount of MDA and other aldehydes (TBARS) were not affected, suggesting that antioxidant activities were sufficient to prevent from substantial ROS-mediated membrane damage during the $3 \mathrm{~h}$ stress exposure, even when migration was inhibited. In such short-term experiments (i.e. $<24$ h), it seems that only stronger oxidative stress such as UV- or herbicides-induced leads to noticeable lipoperoxidation (Rijstenbil, 2005; Wang et al., 2011).

New evidences on the interplay between behavioural and physiological response to lighttemperature stress in epipelic microphytobenthos

In response to HL alone, diatoms which were free to move (i.e. in the controls) could reach deeper layers of sediment with lower light conditions, potentially closer to their photosynthetic optimum (Kromkamp et al., 1998). This downward migration contributed to a reduction of the deleterious effects of HL observed in Lat A treated samples (i.e. immobilized cells at the surface of sediment) such as an enhanced accumulation of Chl $a$ allomers and a slower ФPSII recovery. Our results are in agreement with previous works using Lat A on natural biofilms (Perkins et al., 2010; Serôdio et al., 2012). Similarly, the motile diatoms could reach a depth with lower and more stable temperature, as shown by the in situ temperature depth profiles monitored here. Nevertheless, our measurements were not refined enough to conclude about the steepness of the vertical temperature gradient in muddy sediment, as for light (Paterson and Hagerthey, 2001; Cartaxana et al., 2011). Additionally, high temperature alone is known to directly affect the motility of MPB diatoms, i.e. over $35^{\circ} \mathrm{C}$ cell motility significantly drops-down (Cohn et al., 2003; Du et al., 2012). Such feature might partly explain the stronger photoinhibition observed at $37^{\circ} \mathrm{C}$ in Lat A free samples, together with a direct impact of temperature on physiological mechanisms. 
NPQ developed in the same range of mean values (i.e. 3-4) in situ than during LSRE with HL stress alone. Concomitantly, the DD+DT pool size as well as DES increased. DT synthesis was based not only on DD de-epoxidation (as illustrated by DES) but also by additional DT de novo synthesis (Lavaud and Lepetit, 2013; Lepetit et al., 2013) which enlightened the high level of stress the cells were exposed to. Whatever the source, additional DT provides higher physiological photoprotection via higher NPQ and/or via higher prevention of oxidative lipid peroxidation (Lepetit et al., 2010; Lavaud and Lepetit, 2013). DT synthesis (DD+DT and DES) is enhanced by the high temperature stress alone (Salleh and McMinn, 2011), and this effect was even stronger in conditions of a coupled HL and high temperature stress. Specifically, DD+DT and DES showed a slower recovery which could represent a feed-back reaction (i.e. related to HL/high temperature impairment of the Calvin cycle activity, Mathur et al., 2014) for the maintenance of a photoprotection capacity to cope with prolonged stressful temperature conditions, even under LL (Lavaud and Lepetit, 2013; Lepetit et al., 2013). When the diatom motility was inhibited by Lat A, DES significantly increased independently of the temperature, and its recovery was slower. This was apparently not due to a higher DT de novo synthesis as illustrated by the similar DD+DT pool size with and without Lat A. Higher DT synthesis in presence of Lat A had no significant effect on NPQ, except for its increased sustainability when in conjunction with high temperature. Higher sustained NPQ (i.e. qI) is known to be related with both sustained DT and photoinhibition in conditions of a strong stress (Lavaud and Lepetit, 2013; Lepetit et al., 2013). As a consequence, the DT quenching efficiency (i.e. the slope of the NPQ-DT relationship) was lower in presence of Lat A, likely due to the differential involvement of DT molecules in NPQ (Lavaud and Lepetit, 2013): in presence of Lat A, the additional DT molecules instead most probably acted as ROS scavengers in prevention of lipid peroxidation (Lepetit et al., 2010) arguing for a pronounced stress (i.e. HL + hight temperature + inhibition of motility) level. 
Although, as expected, the Lhcx pattern in sediment samples was not as clear as the one of monocultures of $N$. phyllepta, one of the dominant species common to the FR and PT MPB communities, the confirmation of the presence of some of the known isoforms was possible. While an isoform with a similar size than Lhcx1 apparently did not react to any of the treatments, we found that the synthesis of two isoforms were enhanced by HL, high temperature and Lat A: one isoform with a size similar to Lhcx3, and one isoform with the size of a dimer which especially positively reacted to high temperature and Lat A treatment. Interestingly, these two isoforms were also present in N. phyllepta. A third isoform (of about $24 \mathrm{kDa}$ ), which was not detected in N. phyllepta, was synthetized in all treatments. Based on our knowledge of the synthesis and roles of Lhcx proteins during prolonged stress, it is reasonable to argue that these isoforms participated, at least in part, to the above described NPQ and XC patterns during the coupled HL and high temperature stress. Interestingly, the Lhcx3 and $24 \mathrm{kDa}$ isoforms strongly reacted to Lat A out of any stress and to a level comparable to HL stress. It suggests that the inhibition of motility might generate a strong preventive physiological answer in diatom cells blocked at the surface of sediment (which can occur in situ during sediment desiccation events for instance), an additional hint that physiological and behavioural photoprotection are closely related in epipelic diatoms. This compensation, together with a stronger NPQ induction and XC activity, was nevertheless not strong enough to prevent immobilized cells from additional photoinhibition, as ФPSII recovery was always lower in Lat A treated samples than in migratory biofilms.

\section{Conclusions and perspectives}

By using a number of methodological novelties in MPB research (a new cryo-sampling method, lipid peroxidation markers for photooxidative stress-TBARS, photosynthetic protein 
markers for physiological protection-Lhcx), the present study clearly strengthens the previous statement of a coupled and complementary action of physiological and behavioural processes in protecting the photosynthetic activity of MPB diatoms in stressful environmental conditions (Perkins et al., 2010, Cartaxana et al., 2011; Serôdio et al., 2012). Moreover, our results bring a physiological basis to the previously reported depression of MPB photosynthetic productivity in summer (Guarini et al., 1997). They emphasize the joint role of temperature and light in limiting, at least transiently (i.e. during emersion), the photosynthetic activity of MPB biofilm in situ. They confirm that high temperature, together with high light, is an important environmental driver which supports seasonal, spatial and potentially latitudinal MPB biodiversity and biomass distribution at the scale of intertidal mudflats along the Atlantic coast of Southern Europe (Guarini et al., 1997; Brito et al., 2013).

Moreover, temperature being expected to increase due to global change (Solomon et al., 2007), further longer-term experiments are required in order to question its importance in modulating MPB photosynthetic activity. Our results support previous works suggesting that MPB gross photosynthesis will most probably not be affected by a small increase (even if significant, i.e. $+1^{\circ} \mathrm{C}$ to $+4^{\circ} \mathrm{C}$ for the most extreme previsions; Solomon et al., 2007) of average temperature (Vieira et al., 2013; Hancke et al., 2014). However, it does not preclude a potential change in the community structure, as observed for associated invertebrate assemblages (Hicks et al., 2011), which might be of importance in driving the whole community response as reported here. Further experiments should rather focus on the cumulative effects of successive extreme events such as heat waves experienced during spring/summer (Schär et al., 2004; Stott et al., 2004), with an emphasis on the 'species/individual' vs. 'community/biofilm' response. 


\section{Experimental procedures}

\section{Study areas and experimental design}

Two intertidal mudflats were sampled along the Atlantic Coast of Southern Europe, in France and Portugal (FR and PT sites, respectively): a macrotidal one in the Baie de l'Aiguillon near Esnandes (FR, $\left.46^{\circ} 15.36{ }^{\prime} \mathrm{N}, 1^{\circ} 8,55^{\prime} \mathrm{W}\right)$ and a mesotidal estuary in the Ria de Aveiro near Vista Alegre $\left(\mathrm{PT}, 40^{\circ} 35^{\prime} \mathrm{N}, 8^{\circ} 41^{\prime} \mathrm{W}\right)$. Both sites are composed of fine muddy sediments (dominant particle size $<63 \mu \mathrm{m}$ ) and are known to be colonized by epipelic diatom-dominated MPB throughout the year (Haubois et al., 2005; Serôdio et al., 2012, respectively).

All experiments were performed consecutively in early summer (weeks 26-27, June-July 2012). For each site, natural migratory MPB was studied in situ over one diurnal emersion period. In parallel, light stress-recovery experiments (LSRE) were carried out in controlled conditions in the laboratory at two temperatures using freshly collected samples (see section below). During LSRE, samples were sequentially exposed to (i) low light (LL) level to determine pre-stress reference state; (ii) high light (HL) intensity to induce photoinhibitory effects; (iii) LL to monitor recovery from HL stress (Serôdio et al., 2012).

\section{In situ measurements}

For each site, the day for carrying out the experiment was selected so that the emersion period matched with maximum light and temperature exposure, i.e. noon/early afternoon low tides. Photosynthetic Active Radiation (PAR) and temperature at the surface of the sediment were assessed every $30 \mathrm{~s}$ with a universal light-meter and data logger (ULM-500, Walz Effeltrich Germany) equipped with a plane light/temperature sensor (accessory of the ULM-500) and a plane cosine quantum sensor (Li-COR). Depth temperature profiles were measured with Hobo sensors (Hobo Pro V2, Massachussets, USA) fixed on a home-made stick that was vertically inserted into the sediment to position the sensors at four $(-0.5 \mathrm{~cm},-2 \mathrm{~cm},-5 \mathrm{~cm},-10 \mathrm{~cm})$. The 
effective photosystem II quantum yield (ФPSII) and the non-photochemical quenching of chlorophyll $a(\mathrm{Chl} a)$ fluorescence (NPQ) of MPB was assessed with a Water-PAM (microfiber version, Walz GmbH, Effeltrich, Germany) as described in Lefebvre et al. (2011). ФPSII was calculated as $\Delta \mathrm{F} / \mathrm{F}_{\mathrm{m}}{ }^{\prime}=\left(\mathrm{F}_{\mathrm{m}}-\mathrm{F}\right) / \mathrm{F}_{\mathrm{m}}$. Rapid light curves (RLCs) with $30 \mathrm{~s}$ light steps were used to measure NPQ vs irradiance (NPQ-E) curves (as recommended in Lefebvre et al., 2011). NPQ-E curves were fitted with the model by Serôdio and Lavaud (2011) in order to estimate $\mathrm{NPQ}_{\max }$ where $\mathrm{NPQ}=\left(\mathrm{F}_{\mathrm{m}}-\mathrm{F}_{\mathrm{m}}{ }^{\prime}\right) / \mathrm{F}_{\mathrm{m}} . \mathrm{F}_{\mathrm{m}}$ and $\mathrm{F}_{\mathrm{m}}{ }^{\prime}$ are the maximum Chl $a$ fluorescence levels measured in dark-adapted and illuminated (at the end of each RLCs light steps) MPB, respectively, while F is the steady-state Chl $a$ fluorescence level measured at the end of each RLC light step, just before $\mathrm{F}_{\mathrm{m}}$ ' was assessed. $\mathrm{F}$ was measured with the application of a non-actinic modulated beam of $455 \mathrm{~nm}$, and $\mathrm{F}_{\mathrm{m}}$ and $\mathrm{F}_{\mathrm{m}}$ ' with the application of oversaturating (about $4000 \mu \mathrm{mol}$ photons $\left.\mathrm{m}^{-2} \mathrm{~s}^{-1}\right)$ light pulses $(800 \mathrm{~ms})$. Because in in situ as well as in laboratory (see below) conditions (i.e. light-responsive migratory biofilm) it is virtually impossible to measure a true $F_{m}$ level, for the calculation of NPQ, $F_{m}$ was in reality the maximum $\mathrm{F}_{\mathrm{m}}$ ' of the respective RLC (i.e. $\mathrm{F}_{\mathrm{m}}{ }_{\max } \sim \mathrm{F}_{\mathrm{m}}$, see Lefebvre et al., 2011).

\section{Light stress-recovery experiments (LSRE)}

LSRE were carried out following a protocol adapted from Serôdio et al. (2012). The top $1 \mathrm{~cm}$ of sediment was collected at the beginning of low tide and immediately transported to the laboratory where it was sieved $(0.5 \mathrm{~mm}$ mesh) to remove debris and macrofauna. Sediment was thoroughly mixed and spread in trays, forming a 2-4 cm thick slurry, and it was covered with seawater from the sampling site and left undisturbed overnight in the dark at room temperature $\left(\sim 20-25^{\circ} \mathrm{C}\right)$. The next morning, the slurry was homogenized and transferred to 24-well plates using a $100 \mathrm{~mL}$ syringe, filling the wells completely (ca. $3 \mathrm{~mL}$ ). The well plates were then exposed to constant LL of $50 \mu \mathrm{mol}$ photons $\mathrm{m}^{-2} \mathrm{~s}^{-1}$, provided by three slide 
projectors (Reflecta Diamator AF, Reflecta GmbH, Rottenburg, Germany) containing halogen lamps (Quartzline DDL 150W, General Electric, USA) to induce the upward migration of MPB. Once the MPB biofilm was formed (typically after $3 \mathrm{~h}$ ), the plates were transferred to a water bath of constant temperature of $25^{\circ} \mathrm{C}$ or $40^{\circ} \mathrm{C}$ and exposed to constant LL for $30 \mathrm{~min}$. These two experimental temperatures were defined based on a previous study (Blanchard et al., 1997) which defined $25^{\circ} \mathrm{C}$ as an optimum and $35-40^{\circ} \mathrm{C}$ as an extreme maximum for the photosynthetic productivity of MPB. A fixed volume $(200 \mu \mathrm{L})$ of Lat A solution (10 $\mu \mathrm{M}$ final concentration) or of filtered sea water (Control samples: Ctrl) was added to each well. Lat A solution was freshly prepared daily from a $1 \mathrm{mM}$ stock solution of purified Lat A (SigmaAldrich) dissolved in dimethylsulfoxide and stored at $-20^{\circ} \mathrm{C}$ (Cartaxana and Serôdio, 2008). After 15 min waiting for the inhibitor to diffuse, the plates were exposed to HL $(1200 \mu \mathrm{mol}$ photons $\left.\mathrm{m}^{-2} \mathrm{~s}^{-1}, 3 \mathrm{~h}\right)$. This light dose $\left(12.96 \mathrm{~mol}\right.$ photons $\left.\mathrm{m}^{-2}\right)$ was previously shown to be excessive for MPB photosynthesis (Serôdio et al., 2012). After 3 h, samples were placed under LL for 15 min. In parallel, additional samples (for both Ctrl and +Lat A treatments) were maintained during $3 \mathrm{~h}$ under continuous LL. Temperature of the sediment in the top 5 mm was regularly checked using the same sensor previously described. The duration of each step described above was always the same, but the timing was adjusted so that HL period always started at the low tide maximum expected in situ.

For each chemical and light treatment (Ctrl and +Lat A; HL or continuous LL), several endpoints were assessed on 3-6 independent samples at three times: just before the HL stress $\left(\mathrm{T}_{0}\right)$, at the end of the HL stress and after $15 \mathrm{~min}$ of LL recovery (Recov). For the experiments with FR samples, Chl $a$ fluorescence was measured using an Imaging-PAM fluorometer (Maxi-PAM M-series, Walz GmbH, Effeltrich, Germany) and samples were collected for further quantification of photosynthetic pigments, lipid peroxidation, and Lhcx proteins. For PT samples, Chl $a$ fluorescence was measured with a FluorCAM 800MF, open version (PSI, 
Brno, Czech Republic, see Serôdio et al., 2013). Samples were collected for the same analyses than for FR site, except that pigments were not quantified. Samples were collected for the same analyses than for FR site, except that pigments were not quantified. ФPSII and NPQ were calculated as previously described (Serôdio et al., 2012).

For the sediment sampling in wells, a contact-corer specially designed was used to collect rapidly $(<30 \mathrm{~s})$ the uppermost layer of sediment $\left(0.5 \mathrm{~mm}\right.$ thick, $1.5 \mathrm{~cm}^{2}$ area $)$ in each well. It is based on the cryo-sampling of the biofilm, through the contact of the sediment surface with a metal cylinder of known length previously cooled in liquid nitrogen (Laviale et al., submitted). Each core was immediately frozen in liquid nitrogen and stored at $-80^{\circ} \mathrm{C}$ until further analysis.

\section{Pigment analysis}

Pigment extraction and HPLC analysis were carried out following Lepetit et al. (2013), with the exception of the first extraction step which was performed after $24 \mathrm{~h}$ lyophilisation of the sediment cores $\left(3 \mathrm{~mL}\right.$ of $4{ }^{\circ} \mathrm{C}$ mixture extraction buffer: $90 \%$ methanol/ $/ 0.2 \mathrm{M}$ ammonium acetate $(90 / 10 \mathrm{vol} / \mathrm{vol})+10 \%$ ethyl acetate). Extracted samples were analyzed with a Hitachi LaChrom Elite HPLC system equipped with a $10^{\circ} \mathrm{C}$-cooled autosampler and a Nucleosil 1205 C18 column (Macherey-Nagel). The allomerization of Chl $a$ was calculated as the ratio AR $=\mathrm{Chl} a$-allo $/$ tot Chl $a \times 100$ where tot Chl $a=(\mathrm{Chl} a$-allo $+\mathrm{Chl} a$ ' + Chl $a)$ and Chl $a$-allo and $\mathrm{Chl} a^{\prime}$ are the allomer and epimer forms of Chl $a$, respectively. The pigment molar concentrations (expressed as mol. $100 \mathrm{~mol} \mathrm{Chl} a^{-1}$ ) for the xanthophyll cycle (XC) pigments diadinoxanthin (DD) and diatoxanthin (DT) were used to calculate the DD de-epoxidation state $(\mathrm{DES})$ as follows: DES $=[\mathrm{DT} /(\mathrm{DD}+\mathrm{DT})] \times 100$.

\section{Lipid peroxidation}


Lipid peroxidation generated by oxidative stress was estimated by quantifying thiobarbituric acide reactive substances (TBARS) according to Kwon and Watts (1964). Each sample was resuspended in $0.8 \mathrm{~mL}$ of $10 \%$ trichloroacetic acid (TCA, Sigma-Aldrich) and $500 \mathrm{mg} \mathrm{L}^{-1}$ butylated hydroxytoluene (BHT, Sigma-Aldrich) and sonicated (U200S control; IKA Labortechnik, Ika-Werke GmbH, Staufen, Germany) on ice 5 times during 30 s (cycle: 1, amplitude: $30 \%$ ) with intervals of $30 \mathrm{~s}$ to prevent overheating. After extraction, $0.8 \mathrm{~mL}$ of $0.5 \%$ thiobarbituric acid (TBA, Sigma-Aldrich) in $10 \%$ TCA was added. The mixture was heated for $30 \mathrm{~min}$ at $90{ }^{\circ} \mathrm{C}$ and immediately put on ice to stop the reaction. Samples were then centrifuged (15 $\mathrm{min}, 10000 \mathrm{~g}$ ) and $250 \mu \mathrm{L}$ of supernatant were transferred in a 96 well-plate (Sarsted). TBARS were measured by subtracting the nonspecific turbidity (at $600 \mathrm{~nm}$ ) from the TBARS absorption maximum (532 nm) using a Synergy HT absorbance microplate reader (BioTek Instruments Inc., Vermont, USA). Blanks consisted of the same mixture without sediment sample. TBARS concentration was expressed in malondialdehyde (MDA) equivalent (nmol $\mathrm{mL}^{-1}$ ) using an extinction coefficient of $155 \mathrm{mM}^{-1} \mathrm{~cm}^{-1}$. As it was not possible to obtain paired measurements of $\mathrm{Chl} a$ and MDA, values were normalized to the microphytobenthos biomass present at the sediment surface (measured by spectral reflectance: see below). As migration was susceptible to occur in Ctrl samples, only Lat A-treated samples could be compared.

\section{MPB surface biomass}

MPB biomass present in the surface layers of the sediment was estimated by spectral reflectance analysis with a fiber optic spectrometer (USB2000-VIS-NIR, grating \#3, Ocean Optics, Duiven, The Netherlands) according to Serôdio et al. (2009). In particular, measurements were carried out under LL $\left(50 \mu \mathrm{mol}\right.$ photons $\left.\mathrm{m}^{-2} \mathrm{~s}^{-1}\right)$ supplied with an halogen lamp (120W, Plusline ES, Philips Lighting) positioned with a $45^{\circ}$ angle to the sediment 
surface while the sensor was at a fixed distance $(\sim 2 \mathrm{~cm})$ perpendicularly to it. Reflectance measurements at 550, 600 and $675 \mathrm{~nm}\left(\rho_{550}, \rho_{600}\right.$ and $\rho_{675}$, respectively) were used to calculate the normalized index $\mathrm{I}_{\text {diat }}$ as follows: $\mathrm{I}_{\text {diat }}=2 \times \rho_{600} /\left(\rho_{550}+\rho_{675}\right)$ (modified from Kazemipour et al 2012). It is based on the spectral peak centered at $600 \mathrm{~nm}$ between the absorbance bands due to the fucoxanthin at $550 \mathrm{~nm}$ and the $\mathrm{Chl} a$ at $675 \mathrm{~nm}$. In comparison to other MPB spectral indices available (Méléder et al., 2010), it was shown to be less affected by water or detritical organic matter contents, thus allowing a better comparison between sites (data not shown).

\section{Lhcx protein analysis}

Protein extraction from sediment cores, SDS-PAGE, Western-blot and ECL immunodetection were carried out following the protocol by Coesel et al. (2009) modified by Lepetit et al. (2013): In order to improve the proteins extraction, sediment samples were exposed to eight freeze thaw cycles in the extraction buffer $(500 \mu \mathrm{L}$ lysis buffer $+500 \mu \mathrm{L}$ protease inhibitor, Sigma-Aldrich, USA) and then incubated at RT (total extraction was $90 \mathrm{~min}$ ). Chl $a$ concentration of extracted samples was determined according to Jeffrey and Humphrey (1975) and samples corresponding to an amount of $0.5 \mu \mathrm{g}$ Chl $a$ were loaded on the gel. Correct blotting was verified by correct transfer of pre-stained protein markers on the PVDF membrane (Amersham Hybond-P, GE Healthcare life Sciences, USA) and by staining gels with Coomassie R-250 (Pierce Imperial Protein stain, Thermo scientific, Rockford, USA). Anti-FCP6 (Lhcx1) from Cyclotella cryptica (Westermann and Rhiel, 2005) and anti-Lhcx6 from T. pseudonana (Zhu and Green, 2010) were applied in a 1:1000 dilution for LR samples overnight (respective incubations with the secondary antibody were $2 \mathrm{~h}$ and $1 \mathrm{~h}$ ). For PT samples, the anti-Lhcx6 antibody did not yield a good signal; anti-FCP6 was used at a dilution of 1:1000 (incubation with the secondary antibody, $1 \mathrm{~h}$ ). Note that because of the species- 
specific immunodetection pattern no quantification per se was possible. However, the comparison with the planktonic models P. tricornutum (Bailleul et al., 2010; Lepetit et al., 2013) and T. pseudonana (Zhu et al., 2010) enabled to possibly distinguish different isoforms including some for which behaviour under HL and temperature stress and their role is known or suspected (see Introduction; Bailleul et al., 2010; Zhu et al., 2010; Lepetit et al., 2013; Büchel, 2014). For P. tricornutum, T. pseudonana and N. phyllepta samples, the procedure was as in Lepetit et al. (2013): exponentially growing cells were exposed to HL stress (2 h at $2000 \mu \mathrm{mol}$ photons. $\left.\mathrm{m}^{-2} \cdot \mathrm{s}^{-1}\right)$ to induce protein expression of several Lhcx isoforms which were separated on the LDS-gel.

\section{Taxonomic composition}

For each site, the first $\mathrm{cm}$ of sediment was collected and stored at $-20{ }^{\circ} \mathrm{C}$ until analysis. Extraction from sediment of the organic fraction, including microalgae cells, was done following Méléder et al. (2007). Preliminary observations of the organic fraction using optical microscopy (Olympus AX70 using 200-fold magnification) were performed to confirm the absence of other classes of microalgae than diatoms. Permanent slides of cleaned diatom frustules (cremation: $2 \mathrm{~h}$ at $450{ }^{\circ} \mathrm{C}$ ) were then prepared in a high refractive index medium (Naphrax; Northern Biological Supplies Ltd, Ipswich, UK). The taxonomic composition was determined to the species level by examining 200-300 frustule valves at 500 fold magnification on the basis of morphological criteria using reference works (Ribeiro et al., 2013, and references therein). Scanning electron microscopy was used to confirm the analysis (JEOL JSM 7600F reaching 50 000-fold magnification).

\section{Statistics}


629 Data presented are mean \pm one standard deviation (SD). Each LSRE experiment was 630 performed twice. Analyses of variance (ANOVA), Tukey's honestly significant difference 631 (HSD) tests, Student's t-tests and linear regressions were performed using the R statistical 632 computing environment ( $\mathrm{v}$ 2.15.1, Ihaka and Gentleman, 1996). In particular, potential 633 interactions between factors were tested considering data set from each site individually, with 634 time ( $\mathrm{T}_{0}$, after $3 \mathrm{~h}$ of $\mathrm{HL}$, after $15 \mathrm{~min}$ recovery under LL), temperature $\left(27^{\circ} \mathrm{C}\right.$ and $\left.37^{\circ} \mathrm{C}\right)$ and 635 chemical ( $\mathrm{Ctrl}$ or + Lat A) as fixed factors. The fact that Chl $a$ fluorescence measurements 636 were made on the same samples over the experiment was also taken into account using the 637 sample name as random effect in a linear mixed effect model (lme function of the nlme 638 package: Pinheiro and Bates, 2000). Comparisons between sites (FR, PT) were performed on 639 data gathered at the end of the LSRE (after recovery), expressed as $\%$ of $\mathrm{T}_{0}$. Site, temperature 640 and chemical were considered as fixed factors. Data normality (Shapiro-Wilk test) and 641 homoscedasticity (Bartlett test) were checked using the residuals.

642 


\section{Acknowledgements}

644 The present study was supported by the Egide/Campus France-PHC Pessoa exchange 645 program $\left(\mathrm{n}^{\circ} 27377 \mathrm{~TB}, \mathrm{JL}\right.$ and JS), the Centre National de la Recherche Scientifique-CNRS 646 (JL), the University of La Rochelle-ULR and the Contrat Plan Etat Région-CPER 'Littoral' 647 (JL, BL post-doc grant), the Region Poitou-Charentes (AB Ph.D. grant), the Deutscher 648 Akademischer Austausch Dienst-DAAD (BL post-doc grant), European Funds through 649 COMPETE, the Portuguese Science Foundation (FCT) through projects PEST (PEst650 C/MAR/LA0017/2013) and MigROS (PTDC/MAR/112473/2009: JS, ML post-doc grant and 651 SF research assistant grant), and through grants SFRH/BSAB/962/2009 (JS), SFRH/BD/ 652 44860/2008 (JE Ph.D. grant). The authors thank Dr. E. Rhiel (Univ. Oldenburg, Germany) 653 and Prof. B. Green (Univ. British Columbia, Canada) for the kind gifts of the anti-FCP6 and 654 of the anti-Lhcx6, respectively, Prof. B. Green for her help analyzing the Lhcx6 Western-blot, 655 C. Pais for her technical assistance with the TBARS quantification, Dr L. Ribeiro (Univ. 656 Lisboa, Portugal) for his help in confirming the identification of N. phyllepta s.1., and $\mathrm{Sr}$ 657 Armindo do Evaristo for his cheerful support. We thank the two anonymous reviewers for 658 their constructive comments on the manuscript.

659 


\section{References}

661

662

663

664

665

666

667

668

669

670

671

672

673

674

675

676

677

678

679

680

681

682

683

684

Admiraal, W. (1984) The ecology of estuarine sediment inhabiting diatoms. Prog Phycol Res 3: $269-322$.

Bailleul, B., Rogato, A., de Martino, A., Coesel, S., Cardol, P., Bowler, C. et al. (2010) An atypical member of the light-harvesting complex stress-related protein family modulates diatom responses to light. Proc Natl Acad Sci USA 107: 18214-18219.

Barnett, A., Méléder, M., Blommaert, L., Lepetit, B., Gaudin, P., Vyverman, W. et al. (2014) Growth form defines physiological photoprotective capacity in intertidal benthic diatoms. ISME J doi:10.1038/ismej.2014.105.

Blanchard, G.F., Guarini, J.M., Gros, P., and Richard, P. (1997) Seasonal effect on the relationship between the photosynthetic capacity of intertidal microphytobenthos and temperature. J Phycol 33: 723-728.

Blanchard, G.F., Guarini, J.M., Richard, P., Gros, P., and Mornet, F. (1996) Quantifying the short-term temperature effect on light-saturated photosynthesis of intertidal microphytobenthos. Mar Ecol Prog Ser 134: 309-313.

Brito, A.C., Benyoucef, I., Jesus, B., Brotas, V., Gernez, P., Mendes, C.R. et al. (2013) Seasonality of microphytobenthos revealed by remote-sensing in a South European estuary. Cont Shelf Res 66: 83-91.

Brunet, C., and Lavaud, J. (2010) Can the xanthophyll cycle help extract the essence of the microalgal functional response to a variable light environment? J Plankton Res 32: 16091617.

Büchel, C. (2014) Fucoxanthin-chlorophyll-proteins and non-photochemical fluorescence quenching in diatoms. In Non-Photochemical Fluorescence Quenching and Energy Dissipation In Plants, Algae and Cyanobacteria. Demmig-Adams, B., Garab, G., Adams, W.W.III, and Govindjee (eds). Advances in Photosynthesis and Respiration, Volume 40., 
pp 259-275. Dordretch, The Netherlands: Springer.

Cartaxana, P., and Serôdio, J. (2008) Inhibiting diatom motility: a new tool for the study of the photophysiology of intertidal microphytobenthic biofilms. Limnol Oceanogr-Meth. 6: 466-476.

Cartaxana, P., Ruivo, M., Hubas, C., Davidson, I., Serôdio, J., and Jesus, B. (2011) Physiological versus behavioral photoprotection in intertidal epipelic and epipsammic benthic diatom communities. J Exp Mar Biol Ecol 405: 120-127.

Cartaxana, P., Domingues, N., Cruz, S., Jesus, B., Laviale, M., Serôdio, J., and da Silva, J.M. (2013) Photoinhibition in benthic diatom assemblages under light stress. Aquat Microb Ecol 70: 87-92.

Chevalier, E.M., Gévaert, F., and Créach, A. (2010) In situ photosynthetic activity and xanthophylls cycle development of undisturbed microphytobenthos in an intertidal mudflat. J Exp Mar Biol Ecol 385: 44-49.

Cid, A., Herrero, C., Torres, E., and Abalde, J. (1995) Copper toxicity on the marine microalga Phaeodactylum tricornutum - Effects on photosynthesis and related parameters. Aquat Toxicol 31: 165-174.

Coelho, H., Vieira, S., and Serôdio, J. (2011) Endogenous versus environmental control of vertical migration by intertidal benthic microalgae. Eur J Phycol 46: 271-281.

Coesel, S., Mangogna, M., Ishikawa, T., Heijde, M., Rogato, A., Finazzi, G., Todo, T., Bowler, C., Falciatore, A. (2009) Diatom PtCPF1 is a new cryptochrome/photolyase family member with DNA repair and transcription regulation activity. EMBO Rep 10: $655-661$.

Cohn, S.A., Farrell, J.F., Munro, J.D., Ragland, R.L., Weitzell, R.E., and Wibisono, B.L. (2003) The effect of temperature and mixed species composition on diatom motility and adhesion. Diatom Res 18: 225-243. 
Consalvey, M., Paterson, D.M., and Underwood, G.J.C. (2004) The ups and downs of life in a benthic biofilm: Migration of benthic diatoms. Diatom Res 19: 181-202.

Davison, I.R. (1991) Environmental effects on algal photosynthesis - Temperature. J Phycol 27: $2-8$.

Depauw, F.A., Rogato, A., d'Alcala, M.R., and Falciatore, A. (2012) Exploring the molecular basis of responses to light in marine diatoms. J Exp Bot 63: 1575-1591.

Du, G.Y., J.H., O., Li, H., and Chung, I.K. (2010) Effect of light and sediment grain size on the vertical migration of benthic diatoms. Algae 25: 133-140.

Du, G.Y., Li, W.T., Li, H.B., and Chung, I.K. (2012) Migratory responses of benthic diatoms to light and temperature monitored by chlorophyll fluorescence. J Plant Biol 55: 159-164.

Goss, R., and Jakob, T. (2010) Regulation and function of xanthophyll cycle-dependent photoprotection in algae. Photosynth Res 106: 103-122.

Goss, R., Pinto, E.A., Wilhelm, C., and Richter, M. (2006) The importance of a highly active and delta $\mathrm{pH}$-regulated diatoxanthin epoxidase for the regulation of the PSII antenna function in diadinoxanthin cycle containing algae. J Plant Physiol 163: 1008-1021.

Grant, J. (1986) Sensitivity of benthic community respiration and primary production to changes in temperature and light. Mar Biol 90: 299-306.

Guarini, J.M., Blanchard, G.F., and Richard, P. (2006) Modelling the dynamic of the microphytobenthic biomass and primary production in European intertidal mudflats. In Functioning of microphytobenthos in estuaries. Kromkamp, J.C., de Brouwer, J.F.C., Blanchard, G.F., Forster, R.M., and Créach, V. (eds). Amsterdam, the Netherlands: KNAW, pp. 187-226.

Guarini, J.M., Blanchard, G.F., Gros, P., and Harrison, S.J. (1997) Modelling the mud surface temperature on intertidal flats to investigate the spatio-temporal dynamics of the benthic microalgal photosynthetic capacity. Mar Ecol Prog Ser 153: 25-36. 
Hancke, K., and Glud, R.N. (2004) Temperature effects on respiration and photosynthesis in three diatom-dominated benthic communities. Aquat Microb Ecol 37: 265-281.

Hancke, K., Sorell, B.K., Chresten, L., Lund-Hansen, L.C., Larsen, M., Hancke, T., and Glud, R.N. (2014) Effects of temperature and irradiance on a benthic microalgal community: A combined two-dimensional oxygen and fluorescence imaging approach. Limnol. Oceanogr. 59: 1599-1611.

Haubois, A.G., Sylvestre, F., Guarini, J.M., Richard, P., and Blanchard, G.F. (2005) Spatiotemporal structure of the epipelic diatom assemblage from an intertidal mudflat in Marennes-Oleron Bay, France. Estuar Coast Shelf S 64: 385-394.

Hicks, N. Bulling, M.T., Solan, M., Raffaelli, D., White, P.C.L., and Paterson, D.M. (2011) Impact of biodiversity-climate futures on primary production and metabolism in a model benthic estuarine system. BMC Ecology. 11: 7.

Hynninen, P.H., Kaartinen, V., and Kolehmainen, E. (2010) Horseradish peroxidase-catalyzed oxidation of chlorophyll a with hydrogen peroxide Characterization of the products and mechanism of the reaction. BBA-Bioenergetics 1797: 531-542.

Hwang, Y.-S., Jung, G., and Jin, E. (2008) Transcriptome analysis of acclimatory responses to thermal stress in Antarctic algae. Biochem Bioph Res Co 367: 635-641

Ihaka, R., and Gentleman, R. (1996) R: a language for data analysis and graphics. J Comput Graph Stat 5: 299-314.

Jeffrey, S.W., and Humphrey, G.F. (1975) New spectrophotometric equations for determining chlorophylls a, b c1 and c2 in higher-plants, algae and natural phytoplankton. Biochem Physiol Pfl 167: 191-194.

Jesus, B., Brotas, V., Ribeiro, L., Mendes, C.R., Cartaxana, P., and Paterson, D.M. (2009) Adaptations of microphytobenthos assemblages to sediment type and tidal position. Cont Shelf Res 29: 1624-1634. 
Kazemipour, F., Launeau, P., and Meleder, V. (2012) Microphytobenthos biomass mapping using the optical model of diatom biofilms: Application to hyperspectral images of Bourgneuf Bay. Remote Sens Environ 127: 1-13.

Kromkamp, J., Barranguet, C., and Peene, J. (1998) Determination of microphytobenthos PSII quantum efficiency and photosynthetic activity by means of variable chlorophyll fluorescence. Mar Ecol Prog Ser 162: 45-55.

Kwon, T., and Watts, B.M. (1964) Malonaldehyde in aqueous solution and its role as measure of lipid oxidation in foods. J Food Sci 29: 294-302.

Lavaud, J., and Lepetit, B. (2013) An explanation for the inter-species variability of the photoprotective non-photochemical chlorophyll fluorescence quenching in diatoms. $B B A$ Bioenergetics 1827: 294-302.

Lavaud, J., and Goss, R. (2014) The peculiar features of non-photochemical fluorescence quenching in diatoms and macrophytic brown algae. In Non-Photochemical Fluorescence Quenching and Energy Dissipation In Plants, Algae and Cyanobacteria. Demmig-Adams, B., Garab, G., Adams, W.W.III, and Govindjee (eds). Advances in Photosynthesis and Respiration, Volume 40, pp 421-443. Dordretch, The Netherlands: Springer.

Lavaud, J., Materna, A.C., Sturm, S., Vugrinec, S., and Kroth, P.G. (2012) Silencing of the violaxanthin de-epoxidase gene in the diatom Phaeodactylum tricornutum reduces diatoxanthin synthesis and non-photochemical quenching. Plos One 7: e36806.

Laviale, M., Ezequiel, J., Pais, C., Cartaxana P. and Serôdio, J. (submitted) A new highresolution method for the fast vertical sampling of intertidal fine sediments.

Lefebvre, S., Mouget, J.L., and Lavaud, J. (2011) Duration of rapid light curves for determining the photosynthetic activity of microphytobenthos biofilm in situ. Aquat Bot 95: $1-8$.

Lepetit, B., Volke, D., Gilbert, M., Wilhelm, C., and Goss, R. (2010) Evidence for the 
existence of one antenna-associated, lipid-dissolved and two protein-bound pools of diadinoxanthin cycle pigments in diatoms. Plant Physiol 154: 1905-1920.

787

788

789

790

791

792

793

794

795

796

797

798

799

800

801

802

803

804

805

806

807

808

809

Lepetit, B., Goss, R., Jakob, T., and Wilhelm, C. (2012) Molecular dynamics of the diatom thylakoid membrane under different light conditions. Photosynth Res 111: 245-257.

Lepetit, B., Sturm, S., Rogato, A., Gruber, A., Sachse, M., Falciatore, A., Kroth, P.G., and Lavaud, J. (2013) High light Acclimation in the secondary plastids containing diatom Phaeodactylum tricornutum is triggered by the redox state of the plastoquinone pool. Plant Physiol 161: 853-865.

Lillebo, A.I., Valega, M., Otero, M., Pardal, M.A., Pereira, E., and Duarte, A.C. (2010) Daily and inter-tidal variations of $\mathrm{Fe}, \mathrm{Mn}$ and $\mathrm{Hg}$ in the water column of a contaminated salt marsh: Halophytes effect. Estuar Coast Shelf S 88: 91-98.

Mathur, S., Agrawal, D., and Jajoo, A. (2014) Photosynthesis: Response to high temperature stress. J Photoch Photobio B 137: 116-126

Méléder, V., Rincé, Y., Barillé, L., Gaudin, P., and Rosa, P. (2007) Spatiotemporal changes in microphytobenthos assemblages in a macrotidal flat (Bourgneuf bay, France). J Phycol 43: $1177-1190$.

Méléder, V., Launeau, P., Barillé, L., Combe, J.-P. , Carrère V., Jesus, B., and Verpoorter, C. (2010) Hyperspectral imaging for mapping microphytobenthos in coastal areas. In: Geomatic solutions for coastal environments. Maanan, M., and Robin, M. (eds). Nova Science Publishers.

Morris, E.P., and Kromkamp, J.C. (2003) Influence of temperature on the relationship between oxygen- and fluorescence-based estimates of photosynthetic parameters in a marine benthic diatom (Cylindrotheca closterium). Eur J Phycol 38: 133-142.

Paterson, D.M., and Hagerthey, S.E. (2001) Microphytobenthos in contrasting coastal ecosystems: Biology and dynamics. In Ecological Comparison of Sedimentary Shores. 
811 Perkins, R.G., Lavaud, J., Serôdio, J., Mouget, J.L., Cartaxana, P., Rosa, P. et al. (2010) Vertical cell movement is a primary response of intertidal benthic biofilms to increasing light dose. Mar Ecol Prog Ser 416: 93-103.

Pinheiro, J.C., and Bates, D.M. (2000) Mixed-models in S and S-PLUS. New York, USA: Springer-Verlag.

Ribeiro, L., Brotas, V., Rince, Y., and Jesus, B. (2013) Structure and diversity of intertidal benthic diatom assemblages in contrasting shores: A case study from the Tagus estuary. $J$ Phycol 49: 258-270.

Rijstenbil, J.W. (2005) UV- and salinity-induced oxidative effects in the marine diatom Cylindrotheca closterium during simulated emersion. Mar Biol 147: 1063-1073.

Roncarati, F., Rijstenbil, J.W., and Pistocchi, R. (2008) Photosynthetic performance, oxidative damage and antioxidants in Cylindrotheca closterium in response to high irradiance, UVB radiation and salinity. Mar Biol 153: 965-973.

Saburova, M.A., and Polikarpov, I.G. (2003) Diatom activity within soft sediments: behavioural and physiological processes. Mar Ecol Prog Ser 251: 115-126.

Salleh, S., and McMinn, A. (2011) The effects of temperature on the photosynthetic parameters and recovery of two temperate benthic microalgae, Amphora cf. coffeaeformis and Cocconeis cf. sublittoralis (Bacillariophyceae). J Phycol 47: 1413-1424.

Schär, C., Vidale P.L., Lüthi, D., Frei, C., Häberli, C., Liniger, M.A., and Appenzeller, C. (2004) The role of increasing temperature variability in European summer heatwaves. Nature 427: 332-336.

Serôdio, J., and Catarino, F. (1999) Fortnightly light and temperature variability in estuarine intertidal sediments and implications for microphytobenthos primary productivity. Aquat. Ecol. 33: 235-241. 
Serôdio, J., Cartaxana, P., Coelho, H., and Vieira, S. (2009) Effects of chlorophyll fluorescence on the estimation of microphytobenthos biomass using spectral reflectance indices. Remote Sens Environ 113: 1760-1768.

Serôdio, J., and Lavaud, J. (2011) A model for describing the light response of the nonphotochemical quenching of chlorophyll fluorescence. Photosynth Res 108: 61-76.

Serôdio, J., Cruz, S., Vieira, S., and Brotas, V. (2005) Non-photochemical quenching of chlorophyll fluorescence and operation of the xanthophyll cycle in estuarine microphytobenthos. J Exp Mar Biol Ecol 326: 157-169.

Serôdio, J., Ezequiel, J., Frömmlet, J., Laviale, M., and Lavaud, J. (2013) A method for the rapid generation of non-sequential light-response curves of chlorophyll fluorescence. Plant Physiol 163: 1089-1102.

Serôdio, J., Ezequiel, J., Barnett, A., Mouget, J.L., Méléder, V., Laviale, M., and Lavaud, J. (2012) Efficiency of photoprotection in microphytobenthos: role of vertical migration and the xanthophyll cycle against photoinhibition. Aquat Microb Ecol 67: 161-175.

Solomon, S., Qin, D., Manning, M., Chen, Z., Marquis, M., Averyt, K.B., Tignor, M., and Miller, H.L. (eds.) (2007) Contribution of Working Group I to the Fourth Assessment Report of the Intergovernmental Panel on Climate Change. In Climate Change 2007: Impacts, Adaptation and Vulnerability. 996 pp., Cambridge University Press, Cambridge, United Kingdom and New York, NY, USA.

Stott, P.A., Stone, D.A., and Allen, M.R. (2004) Human contribution to the European heatwave of 2003. Nature 432: 610-614.

Underwood, G.J.C., and Kromkamp, J. (1999) Primary production by phytoplankton and microphytobenthos in estuaries. In Advances in Ecological Research, Vol 29: Estuaries, pp. 93-153.

van Leeuwe, M.A., Brotas, V., Consalvey, M., Forster, R.M., Gillespie, D., Jesus, B. et al. 

(2008) Photoacclimation in microphytobenthos and the role of xanthophyll pigments. Eur J Phycol 43: 123-132.

Vanelslander, B., Creach, V., Vanormelingen, P., Ernst, A., Chepurnov, V.A., Sahan, E. et al. (2009) Ecological differentation between sympatric pseudocryptic species in the estuarine benthic diatom Navicula phyllepta (Bacillariophyceae). J Phycol 45: 1278-1289.

Vieira, S., Ribeiro, L., da Silva, J.M., and Cartaxana, P. (2013) Effects of short-term changes in sediment temperature on the photosynthesis of two intertidal microphytobenthos communities. Estuar Coast Shelf S 119: 112-118.

Wang, Z.-H., Nie, X.-P., Yue, W.-J., and Li, X. (2012) Physiological responses of three marine microalgae exposed to cypermethrin. Environ Toxicol 27: 563-572.

Waring, J., Klenell, M., Bechtold, U., Underwood, G.J.C., and Baker, N.R. (2010) Lightinduced responses of oxygen photoreduction, reactive oxygen species production and scavenging in two diatom species. J Phycol 46: 1206-1217.

Westermann, M., and Rhiel, E. (2005) Localisation of fucoxanthin chlorophyll a/c-binding polypeptides of the centric diatom Cyclotella cryptica by immuno-electron microscopy. Protoplasma 225: 217-223.

Witkowski, A., Sullivan, M.J., Bogaczewicz-Adamczak, B., Bak, M., Rhiel, E., Ribeiro, L., and Richard, P. (2012) Morphology and distribution of a little known but widespread diatom (Bacillariophyceae), Navicula spartinetensis Sullivan et Reimer. Diatom Res 27: 43-51.

Wu, H.Y., Roy, S., Alami, M., Green, B.R., and Campbell, D.A. (2012) Photosystem II photoinactivation, repair, and protection in marine centric diatoms. Plant Physiol 160: 464-476.

Yun, M.S., Lee, S.H., and Chung, I.K. (2010) Photosynthetic activity of benthic diatoms in response to different temperatures. J Appl Phycol 22: 559-562. 
885 Zhu, S.H., and Green, B.R. (2010) Photoprotection in the diatom Thalassiosira pseudonana:

886 Role of LI818-like proteins in response to high light stress. BBA-Bioenergetics 1797:

887 $1449-1457$.

888 
Figure 1

891

892

893

894

895

896

897

898

899

900

901

902

903

904

905

906

907

908

909

In situ environmental conditions and photosynthetic activity of microphytobenthos during a summer diurnal emersion in Portuguese (Ria de Aveiro, Vista Alegre, A- and C-) and French (Baie de l'Aiguillon, Esnandes, B- and D-) intertidal flats. A- and BPhotosynthetic Active Radiation (PAR, $\mu \mathrm{mol}$ photons $\mathrm{m}^{-2} \mathrm{~s}^{-1}$, black line) at the surface of the sediment and temperature $\left({ }^{\circ} \mathrm{C}\right.$ ) at five depths (surface, $-0.5 \mathrm{~cm},-2 \mathrm{~cm},-5 \mathrm{~cm},-10 \mathrm{~cm}$, grey lines); C- and D- effective PSII quantum yield (ФPSII: open squares) and maximum nonphotochemical quenching of $\mathrm{Chl} a$ fluorescence $\left(\mathrm{NPQ}_{\max }\right.$ : closed circles). Local time (FR: UTC+1, PT: UTC).

\section{Figure 2}

Index of photoinhibition (decrease in DPSII) of microphytobenthos harvested at the French site (FR) during light stress recovery experiments performed on sediment exposed at two temperatures $\left(27^{\circ} \mathrm{C}, \mathrm{A}\right.$ - or $\left.37^{\circ} \mathrm{C}, \mathrm{B}-\right)$ and with an inhibitor of cell motility (+ Lat A) or without $(\mathbf{C t r l}) . \mathrm{T}_{0}$, beginning of the experiment under low light $(50 \mu \mathrm{mol}$ photons $\left.\mathrm{m}^{-2} \mathrm{~s}^{-1}\right)$; HL, after $3 \mathrm{~h}$ high light $\left(1200 \mu \mathrm{mol}\right.$ photons $\left.\mathrm{m}^{-2} \mathrm{~s}^{-1}\right)$; Recov, after $15 \mathrm{~min}$ recovery under low light $\left(50 \mu \mathrm{mol}\right.$ photons $\left.\mathrm{m}^{-2} \mathrm{~s}^{-1}\right)$ following the $3 \mathrm{~h}$ high light; LL, after $3 \mathrm{~h}$ of low light $\left(50 \mu \mathrm{mol}\right.$ photons $\left.\mathrm{m}^{-2} \mathrm{~s}^{-1}\right)$. Values are mean $\pm \mathrm{SD}(\mathrm{n}=6)$.

\section{Figure 3}


Index of photoprotection (NPQ) of microphytobenthos harvested at the French site (FR) during light stress recovery experiments performed on sediment exposed at two temperatures $\left(27^{\circ} \mathrm{C}, \mathrm{A}-\right.$ or $\left.37^{\circ} \mathrm{C}, \mathrm{B}-\right)$ and with an inhibitor of cell motility (+Lat $\left.\mathrm{A}\right)$ or without (Ctrl). Legend as in Fig. 2. Values are mean $\pm \operatorname{SD}(n=6)$.

\section{Figure 4}

Pigment content makers of photooxidative stress (Chl $a$ allomerization ratio: AR) and of photoprotection (DD+DT pool; DD de-epoxidation state: DES) of microphytobenthos harvested at the French site (FR) during light stress recovery experiments performed on sediment exposed at two temperatures $\left(27^{\circ} \mathrm{C}\right.$ or $\left.37^{\circ} \mathrm{C}\right)$ and with an inhibitor of cell motility (+Lat A) or without (Ctrl). A- AR, data from 27 and $37^{\circ} \mathrm{C}$ experiments were pooled, * significant difference compared to Ctrl at the same time $(\mathrm{P}<0.05$, Tukey HSD); BDD+DT pool (in mol.100 mol Chl $a^{-1}$ ), data from Ctrl and Lat A-treated samples were pooled, ** significant difference compared to $27{ }^{\circ} \mathrm{C}$ at the same time $(\mathrm{P}<0.01$, Tukey HSD); C- and D- DES, *** significant difference compared to $\mathrm{Ctrl}$ at the same time $(\mathrm{P}<0.001$, Tukey HSD). Labels as in Fig. 2. Values are mean \pm SD ( $n=12$ : A,B or $n=6: C, D)$ expressed as $\% T_{0}$.

\section{Figure 5}

Western blot of the Lhcx proteins of microphytobenthos harvested at the French site during light stress recovery experiments performed on sediment exposed at two temperatures $\left(27^{\circ} \mathrm{C}, \mathrm{A}-\right.$ or $\left.37^{\circ} \mathrm{C}, \mathrm{B}-\right)$ and with an inhibitor of cell motility (+) or without (-). HL, after $3 \mathrm{~h}$ HL (1200 $\mu$ mol photons $\left.\mathrm{m}^{-2} \mathrm{~s}^{-1}\right)$; LL, after $3 \mathrm{~h}$ of LL (50 $\mu \mathrm{mol}$ photons $\left.\mathbf{m}^{-2} \mathbf{s}^{-1}\right)$. All samples were normalized to the same Chl $a$ concentration $\left(15 \mu \mathrm{g} \mathrm{Chl} a \mathrm{~mL}^{-1}\right)$. A- 
Lhcx proteins were detected using a monoclonal anti-FCP6 (Lhcx1). This antibody detects, similarly as the anti-LHCSR of C. reinhardtii (Lepetit et al., 2013), also Lhcx2 and Lhcx3 in P. tricornutum (strain 'P.t.1') used here as a control. N. phyllepta s.l. (N.p.), the dominant species of the MPB community, was also tested. B- and C- Lhcx proteins were detected using a monoclonal anti-Lhcx6 from T. pseudonana (T.p.) (Zhu and Green, 2010) which also potentially detect Lhcx3 and an Lhcx dimer in P. tricornutum; C- is a special focus on the band between $33-50 \mathrm{kDa}$ in $37^{\circ} \mathrm{C}$ exposed samples. Revelation times were: A- $30 \mathrm{~s}$; B- $15 \mathrm{~s}$ for the bands between $17-23 \mathrm{kDa}, 45 \mathrm{~s}$ for the band between $33-50 \mathrm{kDa}$; C- $30 \mathrm{~s}$; Note that for A- all samples exposed at $37^{\circ} \mathrm{C}$ did not yield satisfying signal; and for B-, the sample HL+ $27^{\circ} \mathrm{C}$ was lost.

\section{Figure 6}

Amount of lipid peroxidation marker (TBARS content in $10^{-6} \mathrm{nmol}$ MDA equivalent $\mathrm{mL}^{-1}$ ) in microphytobenthos harvested at the French site (FR) during light stress recovery experiments performed on sediment exposed at two temperatures $\left(27^{\circ} \mathrm{C}, \mathrm{A}-\mathrm{or}\right.$ $37^{\circ} \mathbf{C}$, B-) with an inhibitor of cell motility (+Lat A). Labels as in Fig. 2. Values are mean \pm $\mathrm{SD}(\mathrm{n}=6)$ normalized to surface biomass $\left(\mathrm{I}_{\text {diat }}\right.$ biomass index $)$.

\section{Figure 7}

Comparison of photoinhibition level (decrease in ФPSII) and photoprotection (NPQ) in microphytobenthos harvested at the Portuguese (PT) and the French (FR) sites during light stress recovery experiments performed on sediment exposed at two temperatures $\left(27^{\circ} \mathrm{C}\right.$ or $\left.37^{\circ} \mathrm{C}\right)$ and with an inhibitor of cell motility (+Lat A) or without (Ctrl). ФPSII 
956 recovery (A) and sustained NPQ (B) after 15 min incubation under LL (50 $\mu$ mol photons $\mathrm{m}^{-2}$

$\left.957 \mathrm{~s}^{-1}\right)$ following $3 \mathrm{~h}$ of $\mathrm{HL}$ exposure $\left(1200 \mu \mathrm{mol}\right.$ photons $\left.\mathrm{m}^{-2} \mathrm{~s}^{-1}\right)$, *** significant difference 958 between sites $(P<0.001$, Tukey HSD). Values are mean \pm SD $(n=6)$.

959

\section{$960 \quad$ Figure 8}

Western-blot of the Lhcx proteins of microphytobenthos harvested at the Portuguese site during light stress recovery experiments performed on sediment exposed at two temperatures $\left(27^{\circ} \mathrm{C}\right.$ or $\left.37^{\circ} \mathrm{C}\right)$ and with an inhibitor of cell motility (+) or without (-). HL, 964 after $3 \mathrm{~h}$ HL (1200 $\mu$ mol photons. $\left.\mathrm{m}^{-2} . \mathrm{s}^{-1}\right)$ treatment; $\mathbf{L L}$, after $3 \mathrm{~h}$ of $\mathbf{L L}$ exposure. All 965 samples were normalized to the same Chl $a$ concentration $\left(15 \mu \mathrm{g} \mathrm{Chl} a \mathrm{~mL}^{-1}\right)$. Lhcx proteins were detected using a monoclonal anti-FCP6 (Lhcx1). This antibody detects, similarly as the 967 anti-LHCSR of C. reinhardtii (Lepetit et al., 2013), also Lhcx2 and Lhcx3 in P. tricornutum 968 (strain 'P.t.1') used here as a control. Note that i) the $27^{\circ} \mathrm{C}$ and $37^{\circ} \mathrm{C}$ samples were not loaded 969 on the same gel but the revelation time was the same (30 s), ii) the use of the monoclonal anti970 Lhcx6 from T. pseudonana did not yield any signal with these samples. 
A

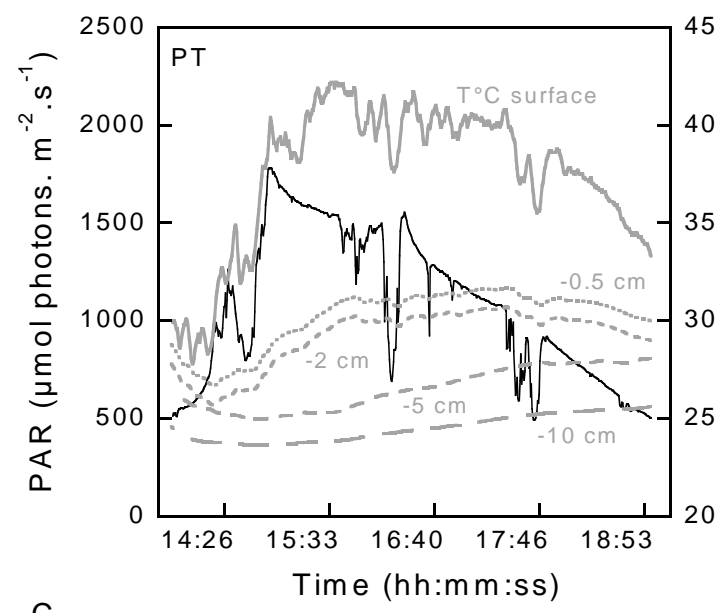

C

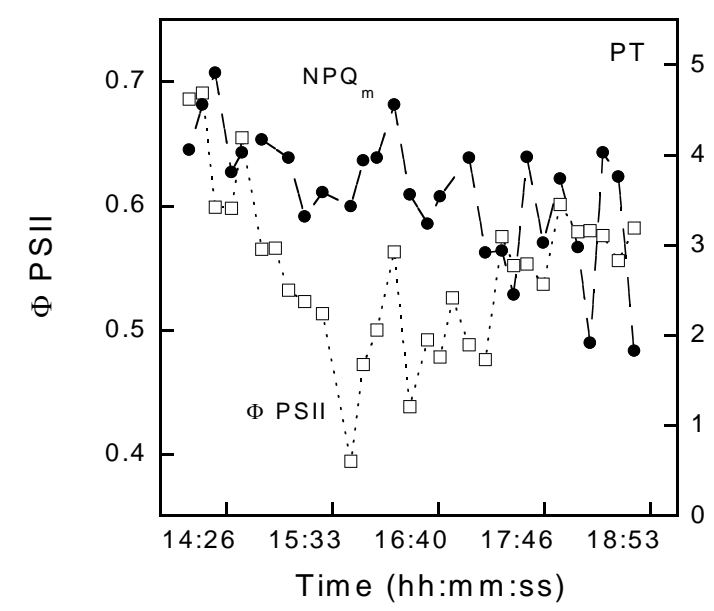

B
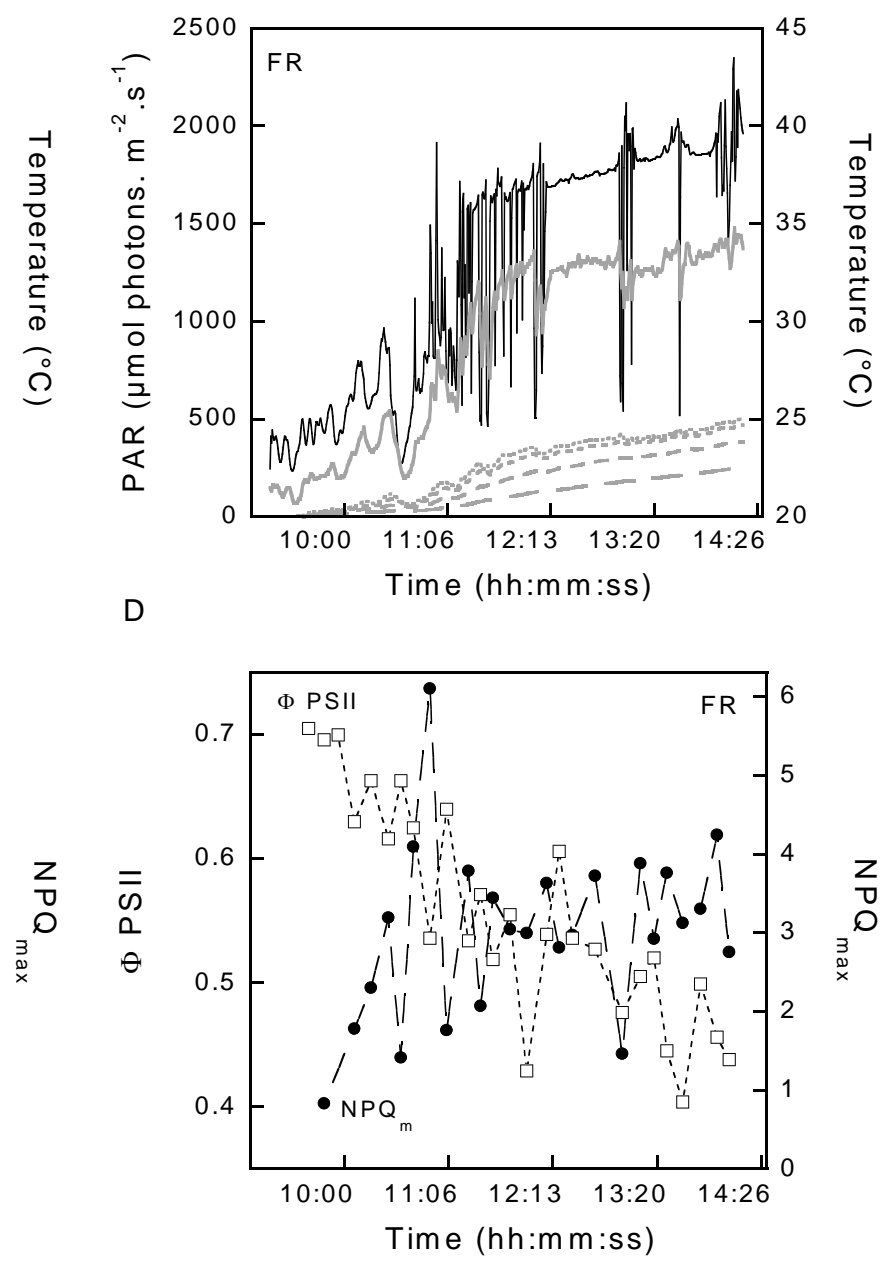

974 
977 Figure 2_Laviale $e t$ al.

A

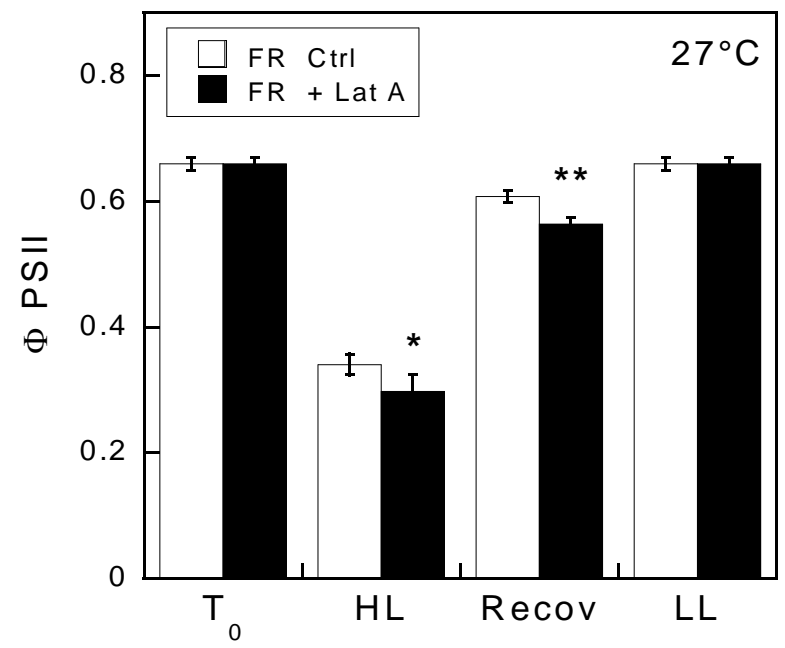

B

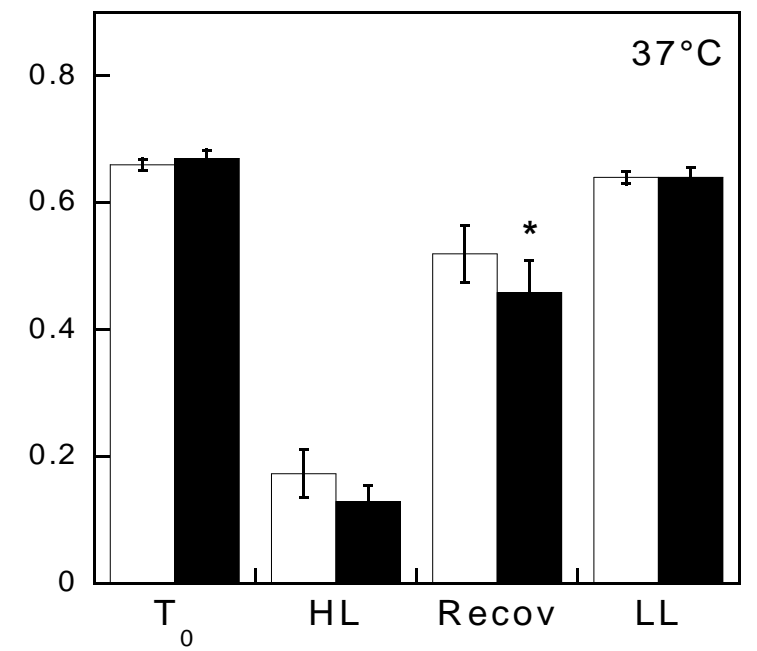

978

979 
981 Figure 3_Laviale et al.

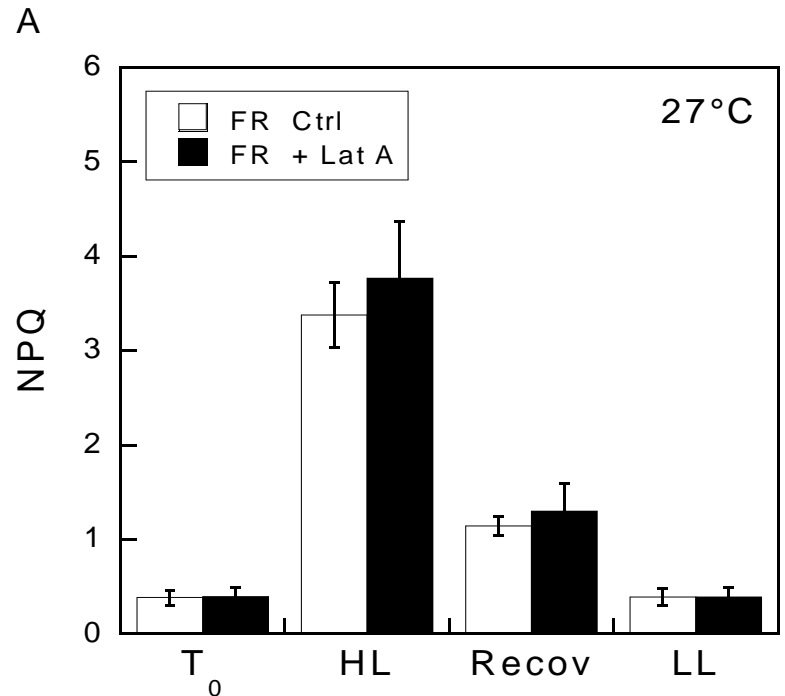

B

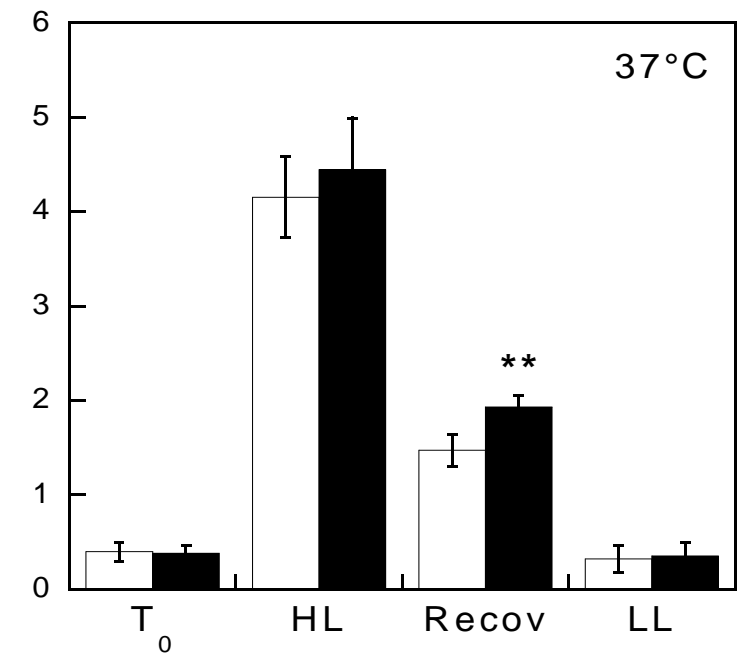

982 
A

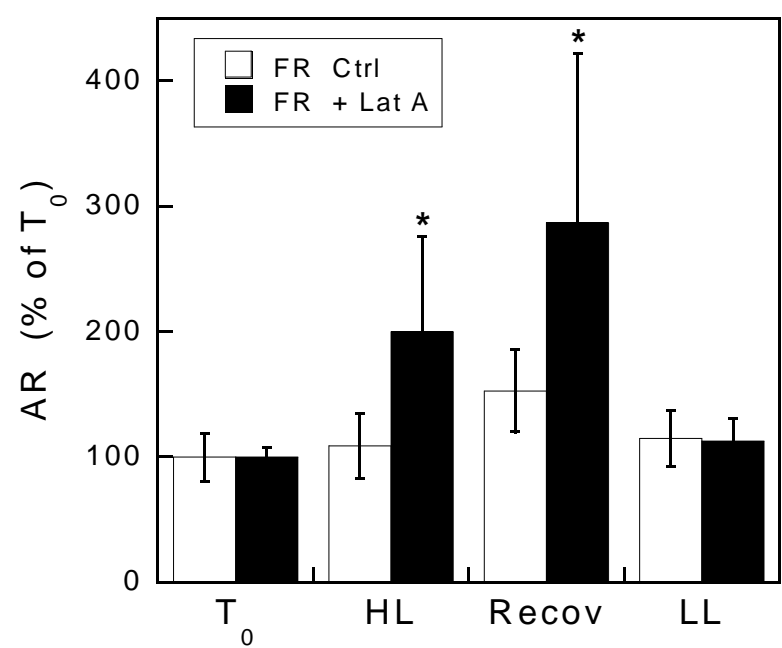

C

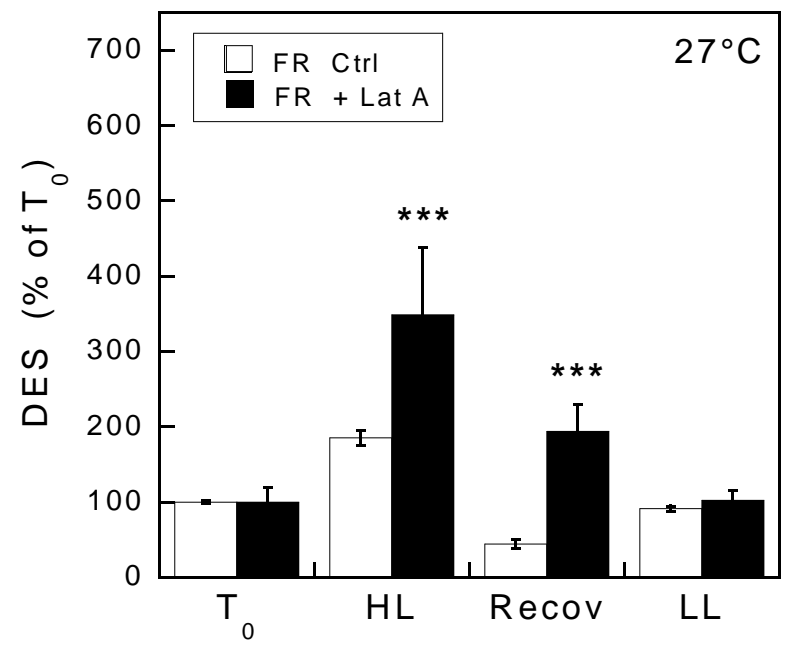

B

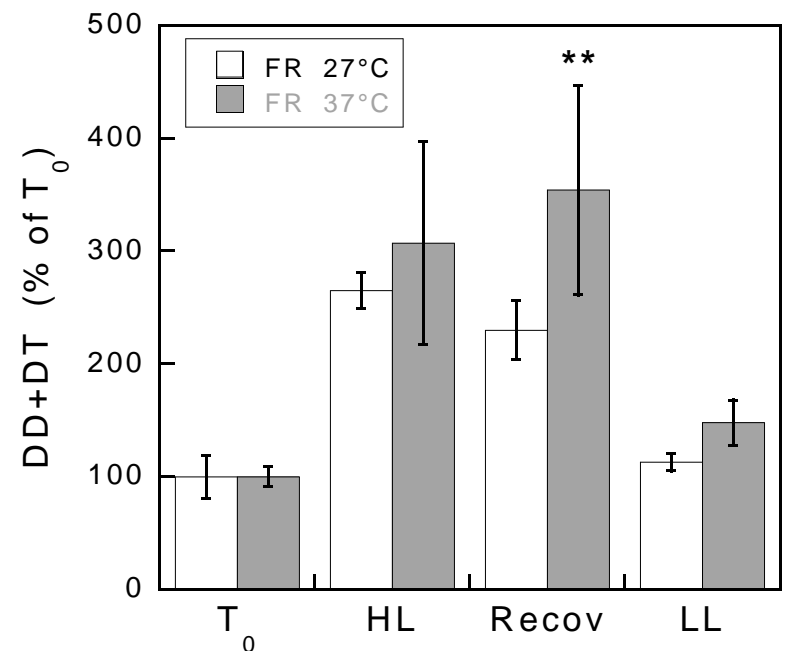

D

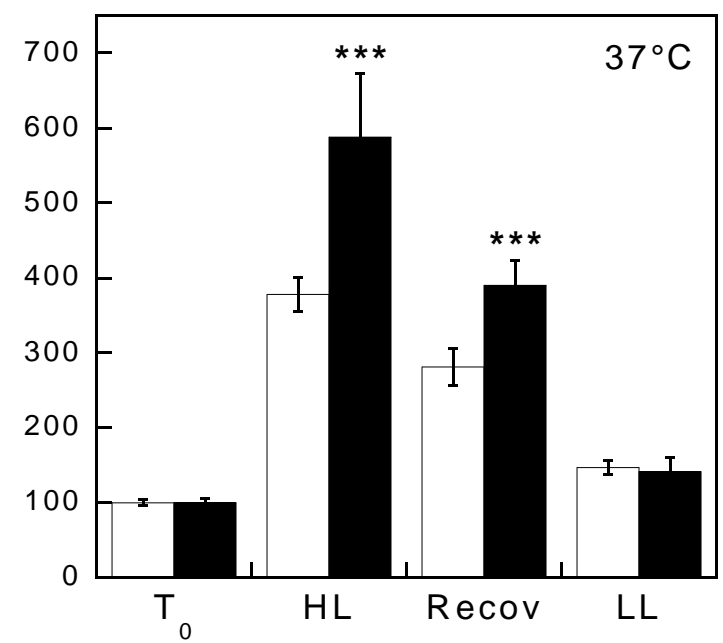

986 
989 Figure 5_Laviale et al.

990

A$27^{\circ} \mathrm{C}$

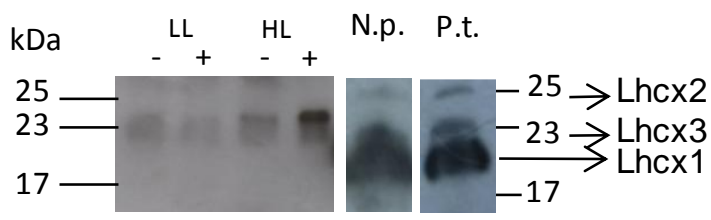

B-
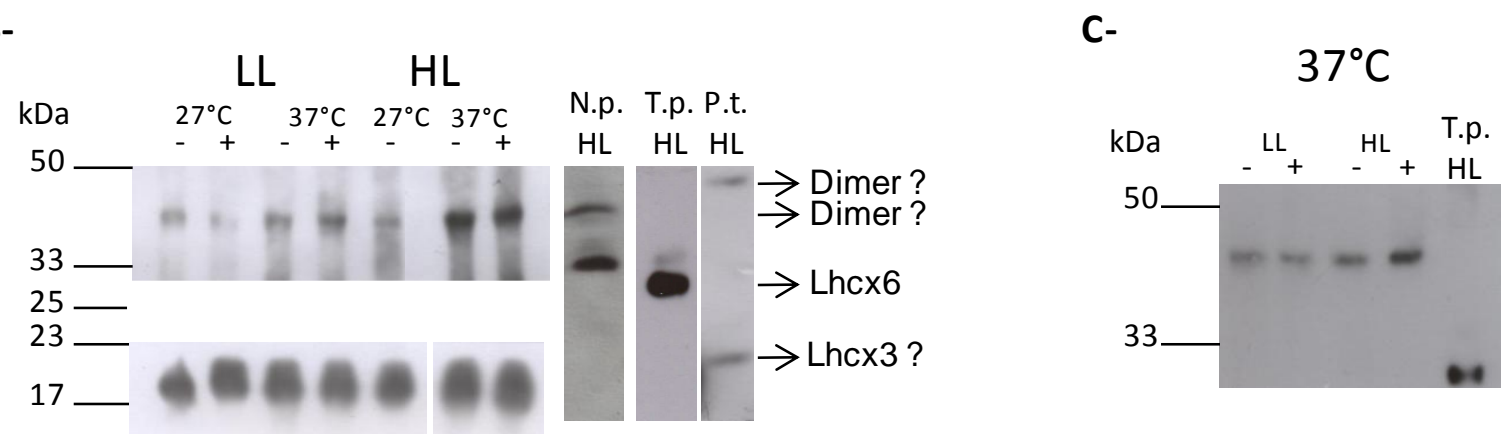

991

992

993 
995 Figure 6_Laviale $e t$ al.

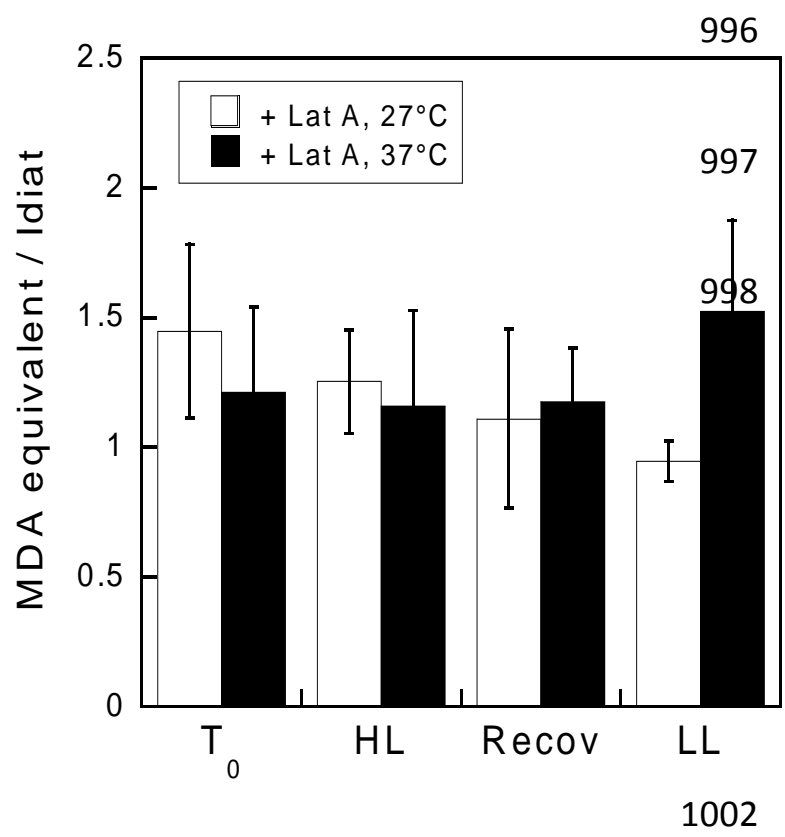

1003

1004 
A

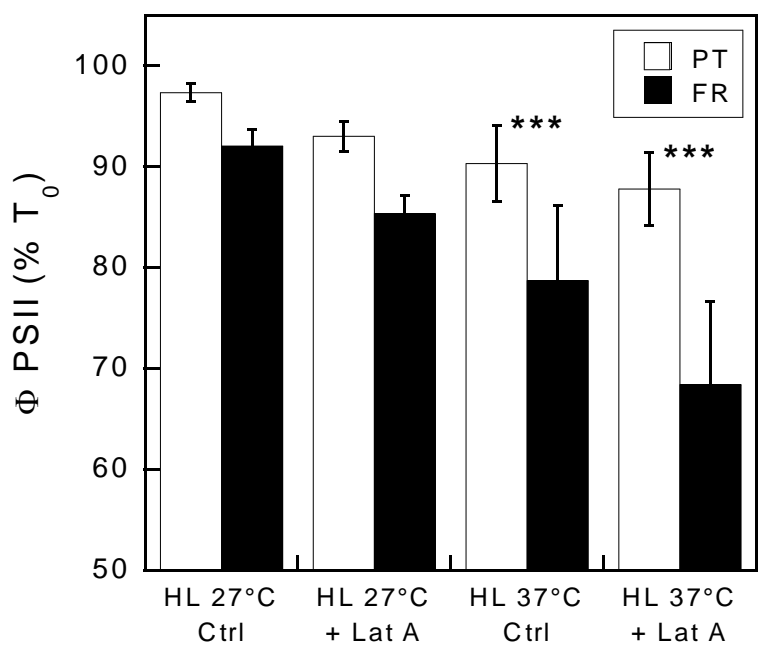

B

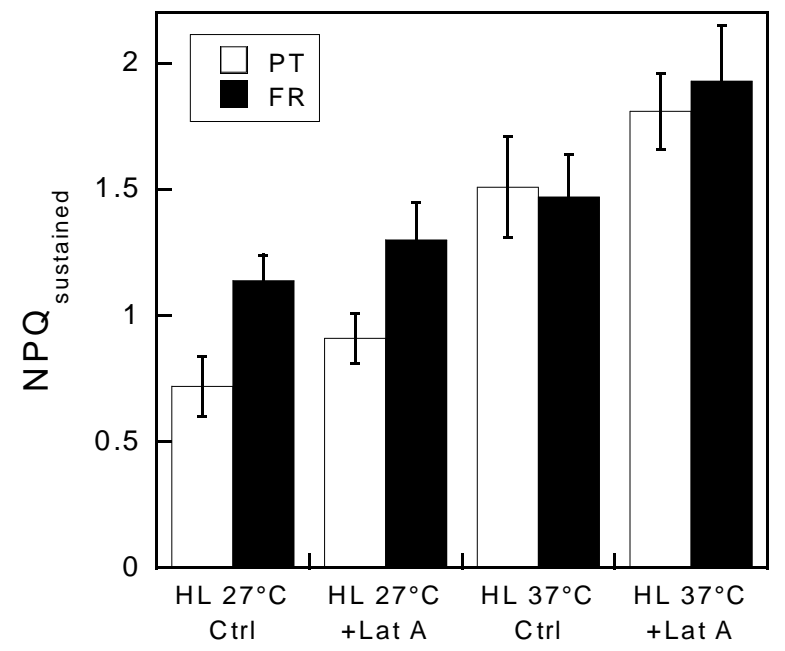

1007

1008 
1010

1011 Figure 8_Laviale et al.

1012

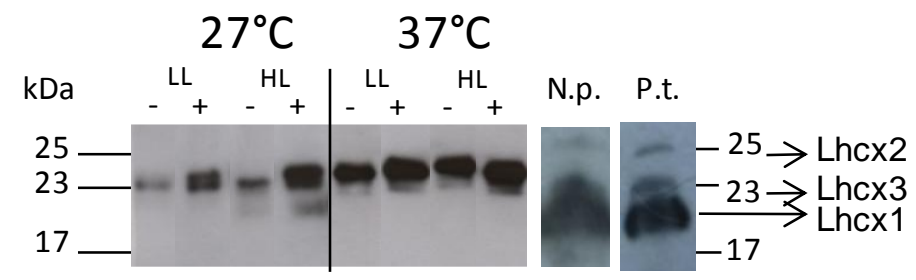

1013

1014 